\title{
Microscopic-Phenomenological Model of Glass Transition and Temperature Dependence of Viscosity-Part I: Foundations of the Model
}

\author{
Karl Günter Sturm
}

check for

updates

Citation: Sturm, K.G

Microscopic-Phenomenological

Model of Glass Transition and

Temperature Dependence of

Viscosity-Part I: Foundations of the

Model. Ceramics 2021, 4, 302-330.

https://doi.org/10.3390/ceramics 4020024

Academic Editors: Michael I. Ojovan, Yuanzheng Yue, Shangcong Cheng and Gilbert Fantozzi

Received: 7 May 2021

Accepted: 26 May 2021

Published: 8 June 2021

Publisher's Note: MDPI stays neutral with regard to jurisdictional claims in published maps and institutional affiliations.

Copyright: (C) 2021 by the author. Licensee MDPI, Basel, Switzerland. This article is an open access article distributed under the terms and conditions of the Creative Commons Attribution (CC BY) license (https:// creativecommons.org/licenses/by/ $4.0 /)$
Diplom-Ingenieur (Chemie), Im Urbruch 3, D-63322 Rödermark, Germany; kgsturm@t-online.de

\begin{abstract}
The glass transition is described as a time- and history-independent singular event, which takes place in an interval dependent on the distribution width of molecular vibration amplitudes. The intrinsic glass transition is not seen as a relaxation phenomenon, but is characterized by a fixed volumetric state at the glass temperature $T g_{0}$. The relaxation behavior of the transport properties depends on the distance to $T g_{0}$. Free volume is redefined and its generation is the result of the fluctuating transfer of thermal energy into condensed matter and the resulting combined interactions between the vibration elements. This creates vacancies between the elements which are larger than the cross-section of an adjacent element or parts thereof. Possible shifts of molecules or molecular parts through such apertures depend on the size and axis orientation and do not require further energetic activation. After a displacement, additional volume is created by delays in occupying abandoned positions and restoring the energetic equilibrium. The different possibilities of axis orientation in space result in the different diffusive behavior of simple molecules and chain molecules, silicate network formers, and associated liquids. Glass transformation takes place at a critical volume $V g_{0}$ when the cross-section of apertures becomes smaller than the cross-section of the smallest molecular parts. The glass transition temperature $T g_{0}$ is assigned to $V g_{0}$ and is therefore independent of molecular relaxation processes. $T g_{0}$ is well above the Kauzmann and Vogel temperatures, usually just a few degrees below the conventionally measured glass temperature $T g_{(q T)}$. The specific volume at the two temperatures mentioned above cannot be achieved by a glass with an unordered structure but only with aligned molecular axes, i.e. in a crystalline state. Simple liquids consisting of non-spherical molecules additionally alter their behavior above $V g_{0}$ at $V g_{l}$ where the biggest gaps are as small as the largest molecular diameter. $T g_{l}$ is located in the region of the crystalline melting point $T_{m}$. Both regions, above and below $T_{m}$, belong to different physical states and have to be treated separately. In the region close to $V g_{0}$ respectively $T g_{0}$, the distribution of vibration amplitudes has to be taken into account. The limiting volume $V g_{0}$ and the formation of apertures larger than the cross-section of the vibrating elements or parts thereof, in conjunction with the distribution width of molecular vibrations as $V g_{0}$ is approached, and the spatial orientation of the molecular axes is key to understanding the glass transition.
\end{abstract}

Keywords: viscosity; glass temperature; glass transition; packing density; glass state; liquid state

\section{Introduction}

Transport properties are one of the key properties for characterizing internal processes in liquids. Molecular kinetic processes during the transition from liquid to glass have a strong influence on many critical processes in nature and technology, such as volcanism or the physical aging of polymers.

The definition of the upper limit from the liquid to the gaseous state does not cause any problems, however the relations of the liquid state to the vitreous state are not unambiguously clear. These relations are of worldwide interest and are considered to be an unresolved problem of solid state physics [1-3]. 
Since the beginning of the last century, a connection between the liquid and the glassy state has been discussed in such a way that glasses were considered to be "frozen" liquids with long term viscous properties. The glass transition is usually interpreted as a loss of thermal equilibrium due to different time scales used in experimental studies and the molecular relaxation time. According to these ideas, there is no definite glass temperature, but only a glass transition or transformation temperature $\operatorname{Tg}(q T)$, which depends on respective cooling/heating rates $q T=( \pm) \mathrm{d} T / \mathrm{d} t$. However, for a cooling rate moving towards 0 the idea of a thermodynamically based glass temperature which corresponds to a phase transition of the 1st or 2nd order has been discussed.

Therefore, a challenging question arises as to whether transport properties such as viscosity in the normal liquid range have something to do with the glass state, or in other words: does a function describing the dependence of viscosity on temperature require a limit value parameter above the absolute zero point?

The idea that the presence of "free volume" between molecules was the reason for the mobility of liquids emerged in 1870 with van der Waals' dissertation and experienced a renaissance in the 1950s. However, there is currently no agreement on the type, scope, and distribution of this free volume. In particular, there is no generally accepted theory on the generation of additional empty space, as even for crystalline solid bodies the occupied space is larger than the corresponding sum of the molecular volumes. Thus it is not surprising that still in recent years the main work dealing with glass transition concentrates on temperature dependence and not on dependence on specific volume and thermal expansion.

In 1980, the author developed an equation based on the assumption that relative changes of viscosity (or other transport properties) are proportional to the relative change of free volume [4]. Due to the (erroneous) simple substitution of $V$ by $T$, a power equation with three material-dependent parameters was developed, which provided very good results in the calculation of viscosity values for polymers and inorganic glasses as well as in super-cooled simple molecular liquids in the range outside the glass transition interval. In addition, one of the parameters was almost perfectly consistent with the $T g$ values from the literature. In the case of simple molecular liquids in the normal liquid regime, however, large deviations can be observed, which presumably are attributed to the increasing influence of vapor pressure and the resulting internal structural changes. As will be shown later, volume ratios play a central role in this scenario, but the quantitative relations during the passage of a vibrating element through apertures between surrounding elements are temperature-dependent, according to the model presented.

Starting with the development of mode coupling models (MC) published in 1984 [5-7], which led to a power law equation similar to the author's from 1980, additional to $\mathrm{Tg}$ a second dynamic transition above $T g$ was supposed. As will be shown, the temperature parameter Tc of the MC power law equation may have a volume-dependent origin and may be replaced by the value $V g_{l}$ presented in this study.

There are a lot of competing theoretical models on this topic (e.g., configurational entropy model of Adam and Gibbs [8], energy landscape approach [9,10], random first order transition theory [11], entropic barrier hopping, frustration limited domains, shovel model) (s. Cummins et al. 1997 [12] and Dyre 2006 [13]), bond orientational two-orderparameter model (Tanaka 2012 [14]), jamming scenarios (Liu and Nagel 1998/2010 [15,16]). To date, however, no consistent theory has prevailed without contradiction. There are even reflections negating any transition but assuming a continuous process down to absolute zero (Kivelson et al. 1996 [17] and Hecksher et al. 2008 [18], Elmatad et al. 2008 [19], Pogna et al. 2015 [20]). Still today [21] it is common (in the author's view one of the main inadequate treatments leading to possible erroneous models) to treat low-viscosity regimes above the melting point of the crystalline phase Tm and the high-viscous states in the supercooled region below $\mathrm{Tm}$ as continuum, despite the fact that already by 1958 [22] pre-crystallizing had been discussed to be the cause of changes in viscosity behavior. 
Furthermore, the new model will show that molecular shape and the possibilities of rotation lead to a modified behavior at the characteristic volume $v g_{l}$.

It is well known that self-diffusion as a basic transport phenomenon in the normal liquid state above $\mathrm{Tm}$ is subject to the same temperature and pressure dependence as viscosity. As self-diffusion is independent from external influences it is generally best suited to show temperature and pressure dependence. From a microscopic point of view, the conditions of self-diffusion are best illustrated by the new model.

Based on the theoretically established and experimentally confirmed equivalence between diffusion and viscosity dependence in the liquid range above $T g_{l}$ and due to the rich data material, the subsequent verification of the new model concept was mainly performed using viscosity data. However, this does not mean that the equalization is completely beyond doubt, because the process of self-diffusion is a microscopic one, whereas viscosity has some macroscopic aspects.

Martinez-Garcia et al. [23] stress that the transfer of the results to further transport phenomena should be very likely. This author agrees with a majority of researchers in recent years that the dielectric coefficient has the same temperature dependence as viscosity. This may well be the case but, due to different molecular processes-molecular shifts in viscosity and self-diffusion compared to intramolecular deformations in dielectric measurements - there are doubts about the admissibility of a joint treatment. Of course, volumetric relationships play a role in both cases, but the orientation of the molecular axes in space should have a different influence on the measurements. Higher pressures in particular should have different effects on intra- and intermolecular processes. The results of the dielectric measurements, which are said to be more accurate than viscosity measurements but decouple slightly from the latter when approaching $T g_{0}[2,24]$, are therefore not included in the study.

It is, according to the author's understanding, imperative and of fundamental importance for the precise prediction of liquid characteristics to involve the glass transition into the theory of the liquid state.

Pioneer studies and comprehensive surveys on the subject are presented, for example Kauzmann, 1946 [25], Tool, 1947 [26], Fox and Flory, 1950/1954 [27,28], Ritland, 1953 [29], Rost 1955 [30], Williams et al., 1955 [31], Cohen and Turnbull, 1961 [32], Kovacs, 1963 [33], Barlow et al., 1965 [34], Koppelmann, 1965 [35], Rötger, 1968 [36], Plazek et al., 1966/1968/1994/1999 [37-40], Davis and Matheson, 1966 [41], Breuer and Rehage, 1967 [42], Kanig, 1969 [43], Goldstein, 1969 [9], Donth, 1981 [44], McKenna and Angell, 1991 [45], Brüning and Samwer, 1992 [46], Böhmer et al., 1993 [47], Angell, 1995 [48], Ediger et al., 1996 [49], Colucci et al., 1997 [50], Rössler et. al., 1998 [51], Ngai, 2000 [52], Tarjus and Kivelson, 2000 [53], Berthier and Garrahan, 2003 [54], Yue et al., 2004 [55], Tanaka, 2005 [56], Dyre, 2006 [13], Ojovan, 2008 [57], Hutchinson, 2009 [58], Liu and Nagel, 2010 [15], Tarjus, 2010 [59], Berthier and Piroli, 2011 [60], Chen et al., 2012 [2], Stillinger and Debenedetti, 2013 [61], Biroli and Garrahan, 2013 [62], Langer, 2013 [63], Miracle and Senkov, 2016 [64], Schmelzer and Tropin, 2018 [65], and Zheng et al., 2019 [66].

\section{Liquid Structure and Glass Formation}

\section{Common Sights of Internal Molecular Mobility in Liquids}

The liquid as well as the gaseous state is generally considered a disordered state. According to the more widely known theories regarding the liquid state molecules have to surmount potential barriers by adjoining molecules when flowing. Surmounting is done in activated discrete jumps. Batschinski, 1913 [67] seems to be the first to neglect energetics and develop a simple equation based on the idea of free volume that allows liquids to flow. Ideas regarding the free volume's redistribution free of additional activating energy were also put forward by Hirschfelder et al., 1935 [68], 1954 [69], however, they could not be established. Fox and Flory, 1950 [27], Cohen and Turnbull, 1961 [32], as well as Grest and Cohen, 1981 [70], turned again to the idea of a free volume, whereby Cohen and Turnbull underlined, however, with reference to the diffusion theory in Glasstone, Laidler, and 
Eyring, 1941 [71], that part of the molecules of a liquid were in an activated state ("5-10\%"). They stated that molecules move with gas kinetic velocity and are temporarily captivated in a "cage" formed by adjoining molecules. Due to occasional variations in density, a hole opens up on a cage that is large enough to allow a substantial displacement of the molecule contained in it. A diffusive movement then only occurs when another molecule has reached the newly formed empty space before the first molecule returns to its original position. They underlined also that this diffusion in their understanding is not based on activation in the normal sense but is rather the result of a redistribution of the free volume within the liquid. In 1967 Chen and Turnbull [72] reiterated, in accordance with the model introduced here, that " $\eta$ depends primarily on configuration rather than temperature per se."

\section{Foundations of the New Microscopic Phenomenological Model}

\subsection{Origin of Internal Fluctuations of Free Volume and Implications Thereupon}

In condensed matter the vibrating elements-molecules, atoms, ions, chain segmentsin the matrix are positioned such that the intermolecular attractive and repulsive forces are in equilibrium. This basic principle should be temperature-independent. An input of temperature energy leads to increasing vibration amplitudes. If the distances between the centers of the molecules remained unchanged, the repulsive forces become larger. According to Le Chatelier's principle, therefore, the distances between the elements must increase in order to maintain the equilibrium of the forces. This is considered the normal thermal expansion of solids and liquids.

The transfer of thermal energy into the molecular matrix cannot be uniform but fluctuates in time and space. In succession the elements of the liquid matrix vibrate around temporally and locally fluctuating centers and, in immediate consequence, the equilibrium of attractive and repulsive forces become disturbed (see Figure 1). As every movement of an element out of its equilibrium position causes a spontaneous evasive movement of the neighbors, the whole matrix is influenced.

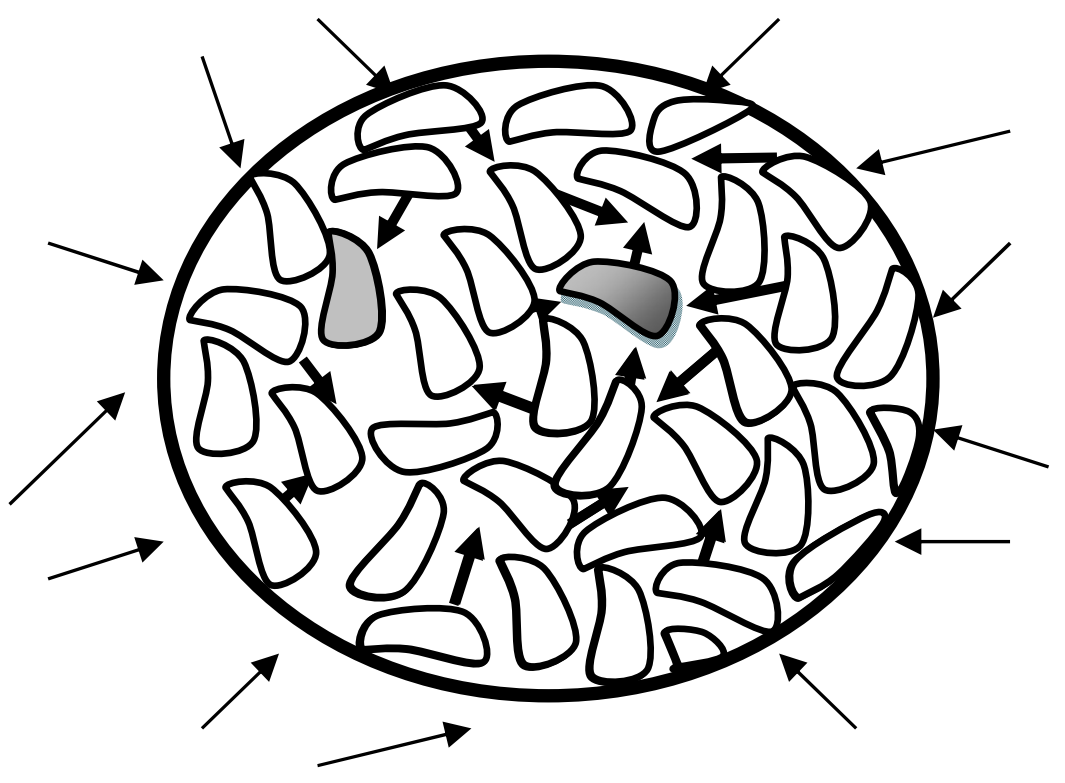

Figure 1. Diffusion process (schematic-2D view). The long arrows in Figure 1 symbolize the transfer of temperature energy by external impulses of gas molecules or radiation coming from all directions in irregular intervals, stimulating the molecules of the liquid matter to vibrate inharmoniously. The vibration frequencies and amplitudes are distributed around a mean value. The short arrows demonstrate that the molecular centers and the axes may tend to move in different directions (the drawn vectors are not arranged correctly). The drawn molecules demonstrate the field limitations. 
As mentioned above, it is the general and undisputed physical view that the molecules in a matrix of condensed matter attempt to reach the most energetically favorable equilibrium position. In the case of spherical molecules, this state, and the optimum distance between the molecular centers, should always be present. In the case of non-spherical particles, on the other hand, axis alignment determines the distance between the molecular centers. In a liquid, molecular axes are not evenly arranged in space and, due to the undirected repulsion forces of neighboring molecules, tend to rotate in all directions of space. Due to local mutual hindrances by adjacent molecular fields, however, it should hardly be possible to rotate in a single operation. Free rotations would require the displacements of neighboring molecules. Assuming that the principle of minimum constraint remains valid even with a $k T$-excited molecular matrix, this is considered improbable.

Molecules try to position their center of mass in positions of equilibrium, which are characterized by the potential minima, but this is prevented by irregularly aligned axes. The smallest distances between the molecules are achieved with uniformly arranged axes, meaning - contrary to the impetus of entropy—in the crystalline state. This energetically preferred state is aimed for at all temperatures by partial revolutions, but temporarily formed structures with aligned axes cannot be consistent at high $k T$ levels. When approaching $T m$ from higher temperatures, more and more clusters withstand the destructive forces of high-energy neighbors and finally crystallites are formed that solidify the entire matrix. Therefore, the rotational possibilities of the vibrating molecules are crucial for each transition scenario.

From the above situation, it follows that when $T m$ is approached, the number of particles per unit volume decreases as short-lived clusters of aligned molecules are formed resulting in a decrease in the number of translations per unit time and, in immediate succession, in viscosity. The real behavior of almost all investigated substances seems to confirm this model concept, as the numerical study in part II will show.

Vibrational amplitudes are distributed around a mean value and as long as the spatial changes consist only of a normal volume increase of the thermal expansion, interpenetrations of the molecular components are not possible because of the size of the cavities being too small. A critical event is created by the random occurrence of combined actions of a certain number of elements, then evasive movements can intensify and create temporary free spaces and openings. The number and size of such short-lived apertures depend on the temperature and are distributed around an average value.

If the gaps are larger than the cross-section of an adjacent element, a shift of this element in principle, wholly or partly with a molecular part, is possible. A further prerequisite that such a change of position can actually occur is the corresponding spatial direction of the adjacent vibration amplitude. Due to their axis-independent orientation, spherical elements should not be subject to any spatial influence, but since the forms of real molecules are only exceptionally perfectly spherical, the projection of the molecular form directed to the aperture is decisive, as shown in Figure 1.

The above picture may appear trivial prima facie, but it is to emphasize the importance of axis orientation, a factor only rarely taken into consideration [41], as crucial for the physics of glass transitions. Above a characteristic temperature $T g_{g}$ the respective gaps of some cavities are large enough for the (partial) occupation by neighboring molecules, if their vibration directions permit it. In the case of a (partial) occupation, the occupying molecule itself leaves behind an empty position, which can only be occupied again with a time delay until the size and direction of the vibration amplitude of an adjacent molecule is suitable. If reoccupation at the second position coincides with the release in the first position, the volume changes are compensated for one another. However, since the abandoned sites cannot be immediately reoccupied, the system reacts by restoring the equilibrium molecular distances and creating additional volume. 
In contrast to the conventional idea of the requirement of activation energy during transport processes, the new model concept assumes that the fluctuating input of thermal energy into the liquid matrix causes only inharmonic oscillations and, as a consequence, leads to the occurrence of cavities between the elements. This is not to say, however, that the energetic conditions have no influence on the displacement of vibrating elements. Using the common corpuscular-atomistic view within the oscillating matrix, mutual penetrations are unthinkable because of the too small vibration amplitudes, as stated above. If there are adjacent openings of the order of magnitude of the cross-section of the vibrating elements, displacements are possible in principle. However, such displacements-percolations-can only occur against the field forces of the adjacent elements acting in the openings. Since the field forces depend on the distance between the cavity boundaries and the center of mass of a passing element, it follows that the smaller the difference between the cross-sections, the higher the required shear forces acting on the passing element must be.

The size of the apertures decreases with falling temperature and at the same time the required shear forces increase, thus as a direct consequence the value of the time constant $\tau$ for the adjustment of the internal structural equilibrium and that of the coefficients for self-diffusion, viscosity, and other transport variables increases.

From the above consideration it can also be derived that the higher the required thrust to pass a gap, the higher the "cooperativity" of the vibrating elements must be. Cooperativity is not a specific physical quantity, but the random interaction of several elements oscillating in the same direction and thus causing a higher shear force.

At the beginning of the work it was mentioned that the new model was based on the theory of free volume. This statement has to be modified insofar as to say it is not the size of the cavities but the width of the apertures that is decisive. Behind a narrow opening there may well be a larger cavity, but this has little or no effect on the energetic conditions during the molecular passage. However, the question arises as to whether there is a fixed relationship, independent of temperature, between generated free volume and the number and width of apertures. Since both repulsive and attractive forces can act, these quantitative relationships are complicated and require further theoretical clarification. Qualitatively, however, the result is a closed picture that clearly illustrates the glass transition.

The fact that self-diffusion depends on the proportion of molecular size to $k T$ may be shown by the following simple (fictive) experiment: (Figure 2).

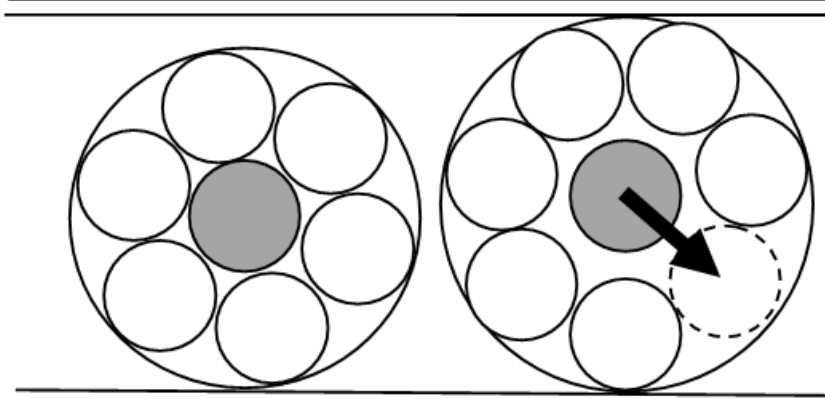

(a)

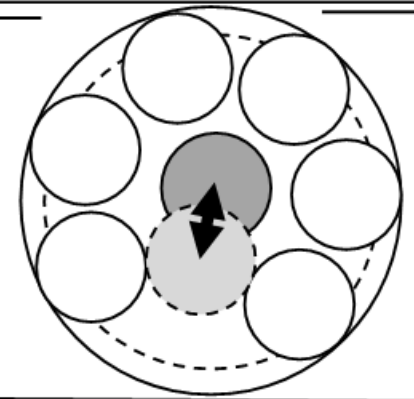

(b)

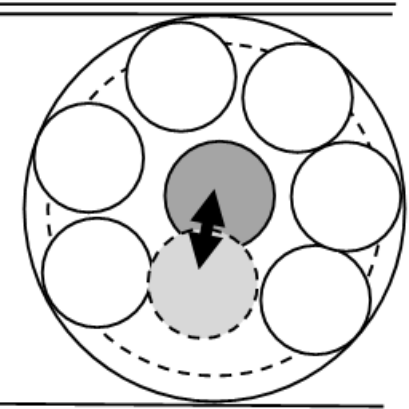

(c)

Figure 2. Geometrical approach to shifting possibilities. In case (a) of Figure 2, all spheres first swing radially at the same time and then crowd together along the boundary. This scenario seems extremely unlikely, if not impossible. Scenario (b) seems to be more realistic and raises the question as to what minimum distance the limit must be in order for at a certain moment a gap to open and the middle sphere to move out of its position. Presumably the situation (c), as an intermediate between $(\mathbf{a}, \mathbf{b})$, comes closest to the truth. 
Seven spheres, six white and one black, were placed in a circle on a vibrating support. The black sphere was situated in the center, encircled by the other spheres. The spheres were surrounded by a circular limitation at a certain distance from the outer virtually enveloping sphere ring. The question arises as to which diameter the limitation must take on so that the black sphere moves out of its central position. If the distance is less than a certain fraction of the sphere diameter the black sphere will indeed move around its central position but cannot leave it. If, however, the limitation distance is larger the black sphere will leave its central position the faster the larger the limitation diameter is. In this experiment, the limitation symbolizes the average vibratory amplitude of the molecules, and thus $k T$, and $\eta$ corresponds to the average shifting velocity. The vibration intensity and frequency concerning the minimum distance of the limitation should have no influence during this experiment. " $\mathrm{Tg}$ ", the limiting temperature between the solid and the liquid state, is reached when the limitation distance has such a value that the black sphere moves out of the central position. The experiment yields the free volume fraction in a simple way without considering energy foundations.

Figure 2 shows some simple shifting possibilities in reference to the dependence of the relation between the radii of the vibrating spheres and the diameter of the outer limitation:

The experiment addresses one of the unsolved, and probably unsolvable [73], problems in physics and mathematics. It is well known that the tightest packing of spheres will become $1-1 / 6 \pi 2^{0.5} \approx 74 \%$ when the spheres are arranged by hand in hexagonal packing. On the other hand, when the spheres are poured into a container and are compacted by mechanical vibrations the packing density reaches at maximum about 63\% [74], meaning that there is no moment where the spheres are packed in the tightest way possible. If one refers this result to the problem of glass formation one may suppose that the situation depicted in Figure 2c would become very interesting ifnon-spherical molecular adequate bodies with varying elasticity modules were used instead of hard spheres. This might perhaps explain the influence of the molecular rotation possibilities and answer the question asked above. Suitable computer simulations should not imply too big a problem.

There is no doubt that viscosity is associated with molecular changes in position within space, as the equivalence to self-diffusion shows. As the number of position changes is strongly temperature-dependent, and since each position change leads to apertures between the elements, viscosity could also be calculated in direct dependence on temperature.

This opens up a challenging question: why look for a relationship with an entity that itself depends on temperature rather than approaching this in a more direct manner? If there is a simple proportionality between temperature and the number and size of apertures without an additional singularity and without further temperature-dependent processes that take place simultaneously, the answer should be: the introduction of volume is unnecessary. However, the fact is that such a simple proportionality does not exist in reality. Already the simultaneous temperature-dependent development of vapor pressure which influences the distribution of internal energy raises questions about simple proportionality. Looking back to the model it should be evident that, at least, there are two different processes increasing volume with temperature, at first the normal thermal expansion as common also for crystalline matter and, in the case of liquids, the generation of additional volume by the aforementioned process (see Figure 3). Both partial volumes do not necessarily exhibit the same temperature dependence. Consequently, the situation could be formulated in such a way that the energetic framework conditions are hidden in the development of the volume (and vapor pressure) and do not necessarily have to be considered additionally for later derivative relationships. Therefore, the introduction of volume into an equation describing the dependency of transport properties on temperature seems very reasonable, and the definition of free volume is of great importance, not least with regard to the influence of pressure, the third main variable of the two-phase system. From a practical point of view, however, it is probably possible to work with a temperature function when the vapor pressure is very low, such as with supercooled liquids. This 
will be shown in part II of the work with viscosity values on silicate glasses and further substances in the supercooled range.

\subsection{Defining the Boundary Line between Liquid and Glass}

\subsubsection{Definitions of Free Volume}

At first glance, the term "free volume" appears to be quite plausible. However, in literature the definitions of "free volume" are very different. Definitions and correlations can be found that are either based on the basic molecular volume $\Sigma V_{M}$, the liquid volume $V l_{0}$ extrapolated to $0 \mathrm{~K}$ (Doolittle [75]), or the crystalline state. In the diagram above (Figure 3) $V_{T K}$ is shown as a definition that defines the volume at the Kauzmann temperature $T_{\mathrm{K}}$, the temperature at which the extrapolated curve of the equilibrium density of the liquid intersects with that of the crystalline state. As this volume, according to the new model, cannot be reached by a glass consisting of non-spherical elements but only in an ordered crystalline state, this definition is regarded as irrelevant as is the reference to $V k_{0}$. The definition $V f_{\text {hs }}$ which is based on the molecular basic volume $\Sigma V_{M}$ (van der Waals volume, hard sphere volume) may not be used for defining free volume as it implies the configurative volume $V_{\text {conf. }}$. The configurative empty space $V_{\text {conf }}$ as the difference between the zero point volume $V g_{00}$ and the molecular volume $\Sigma V_{M}$ is determined by the molecule shape and cannot be reduced further. Even at higher temperatures, it has to be assumed that, due to the too small dimension size, that molecule associated space cannot simply be used by neighbor molecules for position changes. The free volume according to $V f_{\mathrm{SW}}$ [76] should have no direct relation to molecular transport. Figure 4 demonstrates some possibilities to define the free volume.

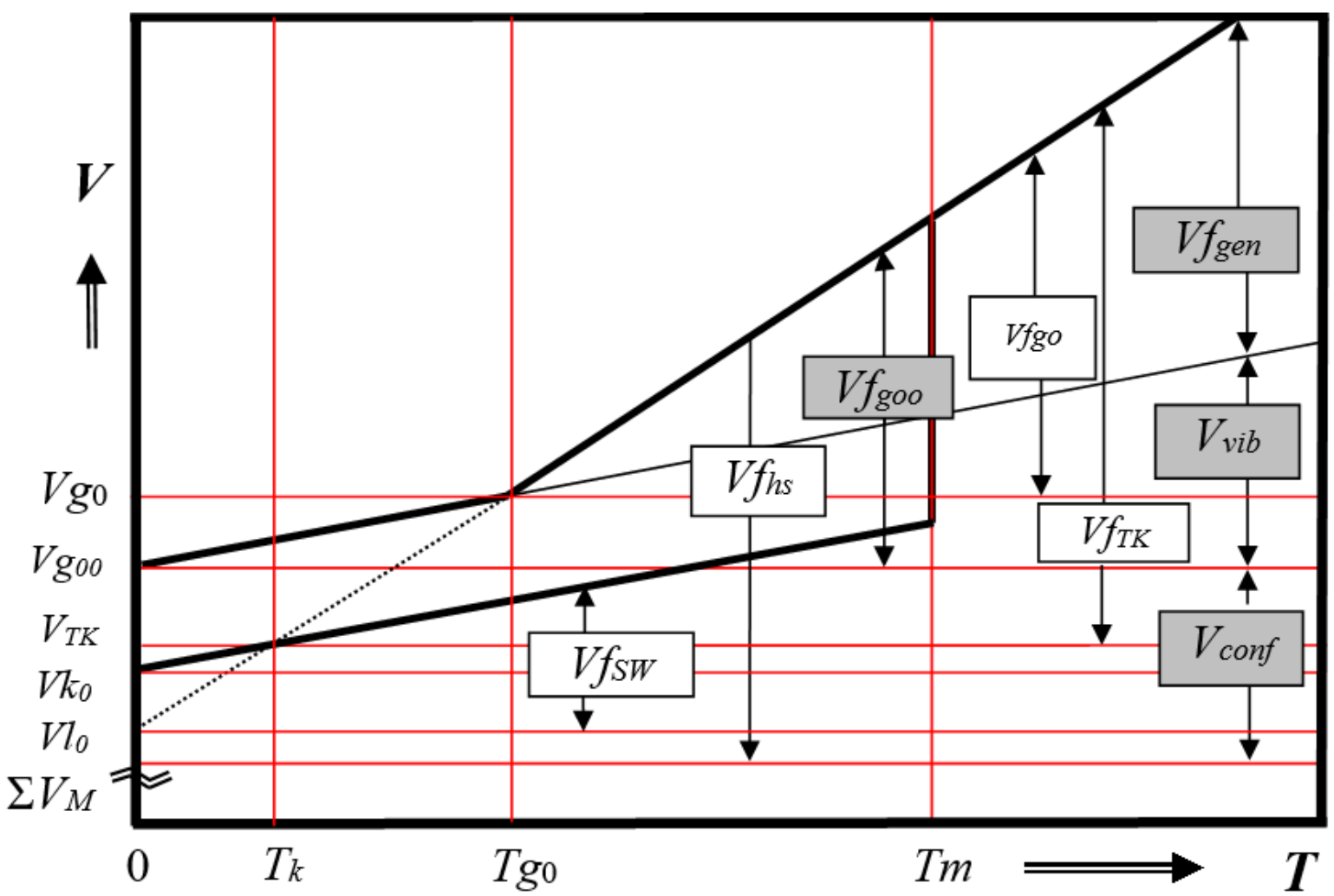

Figure 3. Possibilities to define free volume. (To simplify things, the graphic does not consider the influence of the possibilities of axis orientation and vapor pressure). 


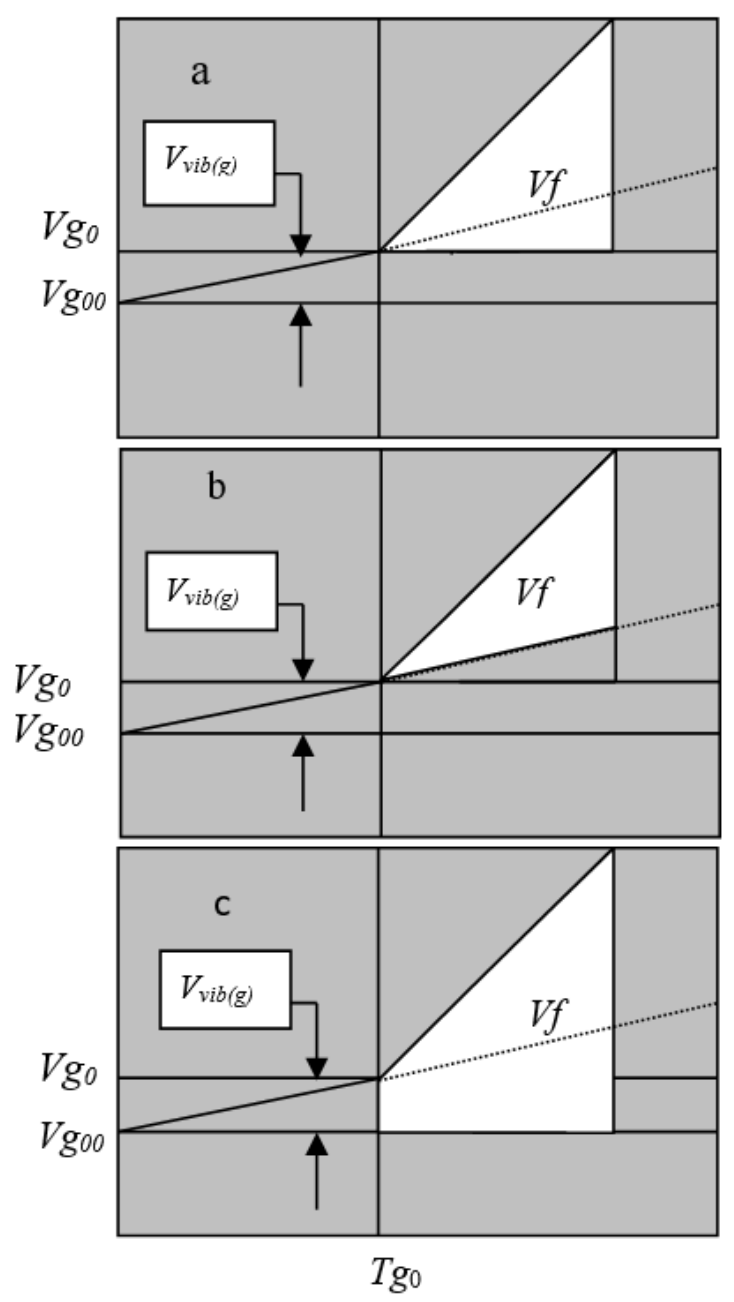

In the case shown in Figure $4 a$, the free volume is generated above $T g_{0}$ respectively $V g_{0}$. It includes the additionally generated volume and that part of the vibration expansion volume above $T g_{0}$.

$$
\begin{aligned}
& V f(T)=V(T)-V g_{0} \\
& \lim T(\eta \rightarrow \infty)=T g_{0} \\
& \lim V(\eta \rightarrow \infty)=V g_{0}
\end{aligned}
$$

Figure $4 \mathrm{~b}$ assumes that only the newly generated volume $V_{\text {gen }}$ is available for transport processes.

$$
\begin{gathered}
V f(T)=V(T)-V_{v i b}(T) \approx V(T)-\alpha_{\mathrm{g}}\left(T-T g_{0}\right) \equiv V_{\text {igen }} \\
\lim T(\eta \rightarrow \infty)=T g_{0} \\
\lim V(\eta \rightarrow \infty)=V g_{0}
\end{gathered}
$$

In Figure $4 c$ the total vibration expansion volume suddenly becomes useable free volume at $T g$.

$$
\begin{gathered}
V f(T)=V(T)-V g_{00}=V(T)-V g_{0}+V_{v i b(g)} \\
\lim T\left(\eta=\eta_{\max }\right)=T g_{0} \\
\lim V\left(\eta=\eta_{\max }\right)=V g_{0}
\end{gathered}
$$

Figure 4. Some possible definitions of free volume (a-c).

According to Figure 3, the specific volume is therefore composed as follows:

$$
\mathrm{V}_{(T)}=\Sigma V_{M}+V_{\text {conf }}+V_{v i b(T)}+V_{g e n(T)}
$$

This definition does not take into account the influence of the pressure, which should also have a large or very small influence on the temperature-independent partial volumes.

How free volume should be defined depends on whether or not one considers the vibratory expansion at $T g, V_{v i b(g)}$ as free volume useable for transport processes and whether one considers a basic volume necessary.

Three differently defined "free" volumes will be discussed below (Figure 4). One case implies different viscosity behavior at the limits of the liquid state.

\subsubsection{Pre-Crystallizing and Supercooling}

As already known from the 1965 work of Barlow, Lamb, and Matheson [34] the viscosity behavior of some simple liquids at the region of the melting point of the crystalline phase changes without visible crystallization and barely perceptible variances in density. Deduced from the course of viscosity temperature dependence of simple liquids in both regions, above and below Tm, a crossover of different molecular transport mechanisms in two temperature regimes was concluded.

In his early 1980/1981 studies [4,77], the author depicted the viscosities of o-terphenyl, the salt blend potassium nitrate/calcium nitrate $60 / 40$, glycerol, and those of the glass standard DGG-1of the German glass society as $\log (\eta)=\mathrm{f}(\log (1-T g / T))$ and demonstrated the different behavior, too. Both o-terphenyl and the salt blend potassium nitrate/calcium 
nitrate $60 / 40$ showed a distinct kink at a certain temperature, which was interpreted as a change in packing density in connection with pre-crystallization appearing in the vicinity of the melting point.

Since the molecular spacing is closer to energetic equilibrium when the molecular axes are oriented uniformly (crystalline state) than when the axes point in all spatial directions (glassy state), the system prefers the crystalline state and attempts to achieve it by partial rotations. This should principally be valid for all temperature ranges. Because of the temporally and spatially fluctuating input of thermal energy into the system, at higher temperatures however, axis alignment is disturbed and prevented.

This structural change cannot remain without having an effect on the transport properties of the molecules. As the temperature gradually decreases, these areas increase and form nuclei to which further molecules attach quickly, which eventually leads to an immediate crystalline solidification. If, on the other hand, cooling takes place very quickly, enlargement of the pre-crystalline zones is impeded and no nuclei can be formed or at least no crystallization can take place. Similar considerations are taken up again in the 2004 work of Blazhnov et al. [78], although the role of nuclei seems somewhat over-emphasized and the negation of influence on viscosity may be questioned. Dyre [79] assumes "fairly large and well-defined crystallites" which are deformed and hardly detectable by standard X-ray or neutron scattering. Semmelhack and Esquinazi [80] investigated "metastable ordered structures" and "unstable crystalline structures" in OTP. Baran et al., 2014 [81] measured OTP with FT-IR and discovered that below $1.2 \mathrm{Tg}$ crystal nuclei appear which are absent above that temperature.

Therefore, one can begin from the premise that with simple liquids approaching Tm, a pre-crystalline state will successively be generated and that, considered physical, there are two different substances above and below the onset of cluster generation.

A coherent equation of the viscosity behavior encompassing both regions with common parameters should therefore be inadmissible. This does not mean that no composite equation can be developed to describe the whole range, although it should be strongly assumed that the properties in the supercooled region are dependent on the measuring and cooling conditions.

\section{Glass Transition/Transformation Range}

\subsection{Time Dependence of Properties Approaching the Glass Transition Regime}

One of the big problems of determining the behavior of properties approaching the glass transition regime is time dependence.

The usual methods of measuring the glass (transition, transformation) temperature, dilatometric or calorimetric measurements with a constant rate of change in temperature $q T= \pm \mathrm{d} T / \mathrm{d} t$, do not give the molecular elements sufficient time to preserve the equilibrium density when the temperature falls below a certain value dependent on qT. The temperature range in which this time dependence is clearly perceivable is defined as the transformation or glass transition range, with the deviation from equilibrium density described as "beginning freezing". It has to be pointed out, however, that the width of the "transformation range" is variable depending on $q T$ and can be moved on the temperature axis. This is also true for the hysteresis range used for definition purposes by Mazurin and Rekhson [82]. Theoretically, there is no upper limit since the thermodynamic equilibrium is fundamentally disturbed when the rate of temperature alteration is higher than the respective relaxation time $\tau$ of the inner structure. The fictive temperature $T f$, i.e., the temperature that the system would have in equilibrium with the current density, deviates increasingly from the current temperature the faster the cooling rate or the higher the relaxation time of the inner structure respectively the higher the viscosity is. In the presented model concept, the volume deviation from the equilibrium density is not interpreted as a beginning freezing. As long as the actual temperature remains above the true glass temperature $T g_{0}$ during the cooling processthe system tries to achieve the equilibrium density and will finally reach this after sufficient waiting time (annealing). Therefore, the "glass transformation", in that 
inadequate sense, is not a special property of supercooled liquids but in general a property of any liquid which is being cooled from any high temperature. In a nutshell, starting at a very high temperature with a fast cooling rate the fictive temperature $T f$, and thus density, may deviate from the equilibrium density even above $T m$. In this case, a stable glass with a large free volume below $T g_{0}$ should be present, which does not react to annealing with respect to its viscous behavior. Figure 5 shows the time-dependent development of the specific volume at constant cooling rate.

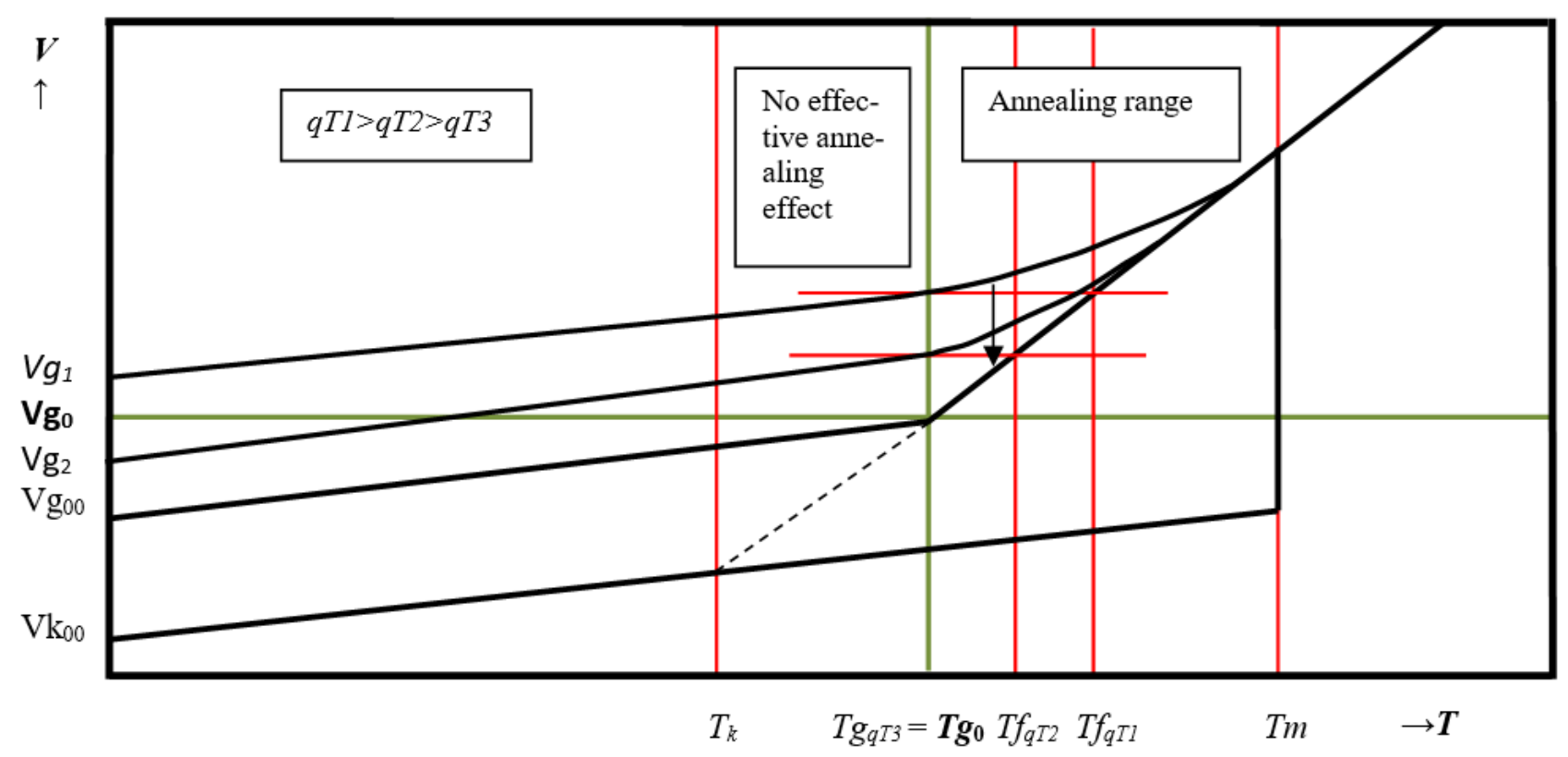

Figure 5. Time-dependent development of the specific volume (schematic). $q T 1, q T 2$, and $q T 3$ are three different cooling rates, the first being the fastest. With $q T 3$ the rate approaches zero and $T g_{q T \rightarrow 0}=T g_{0}$. At $T g_{0}$, the lowest achievable specific volume $V g_{0}$ is reached for a completely disordered material. The path along the dashed line in the direction of $T_{k}$ is not feasible with unaligned molecular axes but only in the (partially) crystalline state. The red horizontal lines yield at their intersections with the equilibrium volume line the fictive temperatures of the obtained glasses with their respective cooling rates. The black downward pointing arrow demonstrates the possibility of reaching a denser glass by annealing. The closer the temperature is to $T g_{0}$ (and the higher the viscosity), the longer the annealing time.

Within the range close to $T g_{0}$ many properties depend not only on temperature but also on time, a fact emphasized by Williams, Landel, and Ferry [31] who established for this range their well-known time-temperature superposition principle. In order to use the WLF equation it is not necessary to know $T g_{0}$ but instead one may use an arbitrary temperature parameter in the transition range within wide bounds. This underlines the above assessment that the deviation from equilibrium density is only indirectly related to glass formation.

The existence of a limit temperature $T g_{0}$ is still the most controversial question within glass science today. The existing uncertainty is caused, among other things, by the functional course of the time-dependent measured $T g$ values, which until the beginning of the millennium was regarded as linear in relation to the logarithm of the cooling rate $q T$, $\operatorname{Tg}(q T)=\mathrm{a}+\mathrm{b} * \log (q T)$. Although Brüning and Samwer [46] discovered a flattening of the curve at very low cooling rates in 1992 on the basis of DSC measurements, the theoretical significance of this was apparently widely overlooked. A second uncertainty comes from the numerical success of the VFT equation, the most commonly used viscosity equation, which yields a limiting temperature well below the glass transition region.

Only below $T g_{0}$, the temperature at which the apertures produced are smaller than the smallest cross-section of the elements and $V<V g_{0}$, should a material be termed "glass", either as an ideal glass or as a real glass, which still contains some free volume, as it is the 
only experimentally attainable state. An ideal glass does not contain free volume available for transport processes and, therefore, it should be a stable matter.

An important question arises as to what happens when the temperature of the out-ofequilibrium-liquid falls below $T g_{0}$. In this case we then have a real glass and a scenario in which small vibratory amplitudes are coupled with an excessive empty space.

The topic of excess free volume is of great practical importance, for example, for the ageing of polymers. This has been studied in the context of the fictive temperature concept by many researchers (for example [26,83-86]) and falls outside the scope of this work, but the model presented here can also contribute to a changed perspective. The basic principle should be that an ideal glass, i.e., a glass without free volume, should not be subject to viscosity-related physical ageing. This again underlines the importance of the knowledge of $T g_{0}$ for glass science.

A further question arises with regard to the classification of glass transformation in the thermodynamic sense. Undoubtedly, the assumption of a singular glass transition temperature influences the thermodynamic evaluation, but if one follows the discussions on this subject (see e.g., Zanotto and Mauro, 2017 [87], Nemilov, 2018 [88]), this is a difficult question that should be dealt with by physicists. From a chemical engineering point of view, the glass state could be considered stable and the supercooled liquid state unstable. These evaluations refer to the existing real possibilities of state changes. Within the supercooled liquid, existing pre-crystalline structures can lead to crystallization over time since molecular rotations and clustering are possible. In contrast, the glass structure below $T g_{0}$ cannot change even after an extremely long waiting period due to a lack of space and associated lack of rotation possibilities. Whether this statement applies in the above-mentioned case of an excessively large "frozen" free volume does not yet seem to have been conclusively clarified.

On the other hand, since undirected molecular axes prevent the molecular centers from positioning themselves on the equilibrium position, there should be an "adaptive force", but this cannot be effective. From the author's point of view, a certain arbitrariness remains, since many substances can crystallize in more than one form with different densities and they are all defined as stable in the thermodynamic sense.

In his 1991 work, Angell [89] emphasized the thermodynamic importance of $T_{0}$ in the VFT equation by comparing the ratios of $T g / T_{0}$ and $T g / T_{k}$, which were the same for some substances where entropy was calculated below $\mathrm{Tg}$. However, this assessment does not call into question the fact that the glass transition at $T g_{0}$ may intervene and the alignment of the molecular axes becomes impossible. In an interesting work of Yamamuro et al. [90] the heat capacity of toluene and ethylbenzene was measured in an adiabatic calorimeter and the configurational entropy was calculated in a convincing manner. The configuration entropy decreased steadily with decreasing temperature and at $\mathrm{Tg}$ (117 resp. $115 \mathrm{~K}$ ) reached a constant value in the glassy state in a sharp bend. The same was observed with 3-bromopentane, 1-butene, o-terphenyl, and the glass-forming plastic crystal cyanoadamantane. Nevertheless, this assessment of Angell seems to have a physical significance with spherical molecules, as previously stated. $T g_{0}$ (derived from $V g_{0}$ ) and $T_{k}$ possibly could be the same if the alignment of the axes in the liquid and the crystalline state are identical.

In two more recent papers [87,91], it was stated that the ultimate fate of glasses is the crystalline state. However, this scenario does not seem very likely, given the increasing mutual obstruction and the lack of usable free volume (see also [66]). Spherical molecules such as noble gases are an exception due to their uniform axes, as already mentioned.

In this context, the conditions of physical vacuum deposition (PVD) [92-94] must also be addressed. During this process, monomolecular layers are successively deposited from the gas phase onto a substrate that has a temperature below the conventional glass temperature $\left.T g_{(\mathrm{DSC}} q T=10 \mathrm{~min} / \mathrm{K}\right)$.

Depending on the substrate temperature, denser or less dense glasses are obtained than those with conventional cooling. The process is used, among other things, to "get deeper into the glass state and to achieve more stable glasses". This phrase is based on the 
idea that suitable measures can be taken to approach the Kauzmann temperature $T_{k}$ or at least the Vogel temperature ( $T_{0}$ in the VFT viscosity equation) or the temperature $T_{2}$ of the ADM theory [8]. As already mentioned, this is not possible in space with irregularly aligned molecular axes, but the path below $T g_{0}$ may only be possible with at least partly parallel aligned axes. If the intersection point at $T_{2}$ or $T_{k}$ exists, then this implies that the vibrating elements have to be arranged in a spatial alignment of the molecular axes at decreasing temperatures, which would then be identical to the crystalline state at their intersection point.

A glass should have a completely disordered state. Each partial order come up closer to the crystalline state and thus to higher densities. However, such a partial order is to be expected with the PVD, because there is a high probability that the molecules, already affected by gravity, will not be arranged perpendicular to the substrate. Compared to the glasses obtained conventionally from liquid by cooling there should be a lack of one spatial component in the precipitated glasses. PVD-glasses, one could call them 2D-glasses, should correspond to an intermediate stage between the completely amorphous and the crystalline state. Therefore, PVD results cannot easily be compared with conventionally obtained results.

\subsection{Influence of Axis Orientation in Space}

The definition of axis orientation is not as simple as it seems on first glance. Molecular elements have interior grades of freedom which may lead to the deformation of molecular shape, particularly those with chain-like molecules. In such cases a cross-area may involve a larger part of a molecule, for example when a short-chained substance has the ability to build up cyclic structures when flowing. Nevertheless, the general fact remains that also with deformed molecules smaller and larger cross-areas exist and, therefore, the term "axis" may be used also in such cases.

The temperature-dependent generation of empty spaces and time-dependent axis orientation are in principle two different processes. In the very high temperature range vibration amplitudes are large and the free spaces generated by combined actions are big enough to become occupied by all neighboring elements independently of their axis orientation in space, only governed by the appropriate direction of modes. That range should be the normal low-viscosity region. When the temperature decreases to $T g_{l}$ all apertures become smaller than the largest molecular diameter of the vibrating molecules. This means axis orientation in space starts to have an influence on translational possibilities. The number of position changes decreases more than would be possible without any alignment restrictions, as translations only happen when the axis of an element is aligned in space such that the geometrical projection onto the gap is smaller than its diameter. Lowering the temperature further finally leads to a situation where the broadest apertures of the void distribution only allow vibrating elements to translate when their cross-sections, totally or partially, are smaller than the diameter of that aperture and, additionally, are pointed to the gap. The limit volume of the liquid state is reached in this situation and can be termed $V g_{0}$. Since at $T g_{0}$ about half of the distribution width of the vibration amplitudes corresponds to $V>V g_{0}$, some cavities are still present at $T g_{0}$ (but cannot contribute to flowability, as explained later). Only when the temperature is lowered further to $T g_{g}$, are all apertures smaller than the smallest molecular cross-section thus making passage impossible. The disordered solid state should then be reached. Figure 6 shows the relationships outlined above: 


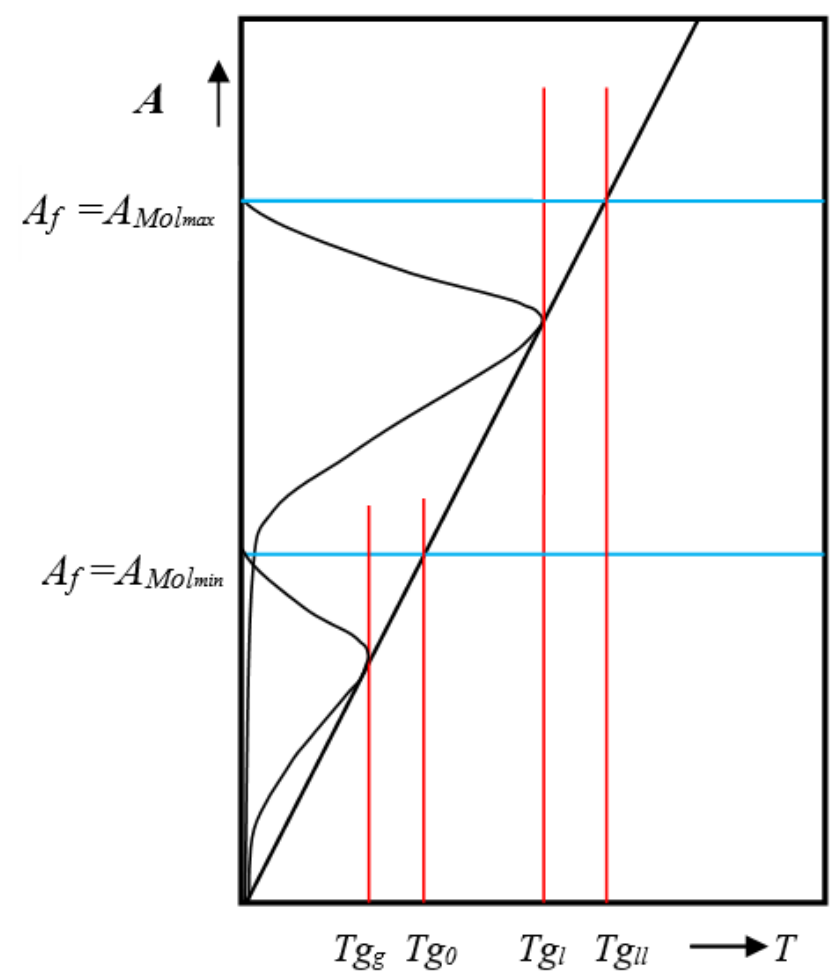

Figure 6. Limitations of viscosity regimes (schematic). The ordinate of Figure 6 exhibits the size of the cross-sectional area of the temperature-dependent gaps $A_{f}$. The blue lines represent the cross-sectional area of the smallest and larges molecular axes. The curved lines symbolize the distribution width of gaps for one distinct temperature characterized by the maximum of curves. For $T<T g_{g}$ all gaps are smaller than $A_{\text {Molmin }}$, the cross-sectional area of the smallest molecular part, thus translational movement is no longer possible. Below $T g_{g}$ there is only the solid glass. Above $T g_{l l}$ the pure liquid state is reached. The upper limit $T g_{l i q}$ of the smallest molecular axes was not drawn for reasons of clarity.

In practice, the ideal glass state without any usable free volume cannot be reached by normal cooling as the waiting times for the molecular rearrangement are too long.

Certainly, there exists empty space in between the molecules also below $T g_{0}$, but that volume (configurative empty space $V_{\text {conf }}$ ) cannot be filled with adjoining molecules or parts of them due to the dimensions of these areas being too small.

Undoubtedly, changes in position below $V g_{0}$, respectively $T g_{0}$, are much less frequent than above, since three states must occur simultaneously:

- a gap must be wider than the cross-section of the smallest dimensional portion of a neighboring molecule,

- the alignment in space of the molecular axis of an adjoining molecule must be pointed to the gap,

- and, last but not least, the direction of the mode of that vibrating molecule must be strictly directed to that aperture.

Therefore, this influence causes transport properties to adopt a new quality and the interesting question arises as to whether there are differences between the various classes of material. Another question is whether the molecular clusters that form in the region of the crystalline melting point, which are considered to be causal for the altered viscosity behavior are related to the possibilities of axis alignment. It should be clear that chain molecules are not able to shift entirely, whereas non-spherical simple molecules have more than one possibility to move through a neighboring opening. As the numerical analysis of simple molecular liquids with data above $T_{m}$ shows, $T g_{l}$ corresponds to the temperature at which the viscosity appears to diverge. In reality this is not the case as fluidity persists until $T g_{0}$ is reached. This partition between two viscosity regimes has 
also been addressed by mode coupling models, such as "dynamic cross-over". In fact, the characteristic temperature $T c$ of these models corresponds approximately to $T g_{l}$ (deducted from $V g_{l}$ ). On the other hand, however, only side-groups or segments of chain molecules can shift through an adjacent aperture so that the viscous behavior corresponds to the simple molecules below $V g_{l}$. Therefore, with chain molecules $V g_{l}$ does not intervene and only $V g_{0}$ controls viscosity. This statement was convincingly verified with viscosity data of polystyrene and polybutene whereby viscosities at a $T / T g$-relations of 1.08 were included into the regression analysis without any kink in the viscosity curve becoming apparent.

Assuming that there is only one driving force that causes molecules to adopt their equilibrium positions, the spatial arrangement of spherical molecules at the glass transition should not deviate from their arrangement in densely packed crystal. If this assessment is correct, glass formed at a temperature $T x$ below $T m$ should have the same density and structure as the crystal at $T x$ formed at $T m$. In the case of spherical molecules, therefore, no distinction should be possible between glass and crystal. Some preliminary tests confirm this important statement using the example of noble gases (argon: $V_{\text {cryst. }} 0.619 \mathrm{~g} \mathrm{~cm}^{-3}$ from viscosity calculations with NIST data $V g_{l}=V g_{0} 0.616-0.622 \mathrm{~g} \mathrm{~cm}^{-3} ;$ krypton: $V_{\text {cryst. }}$. $0.334 \mathrm{~g} \mathrm{~cm}^{-3}, V g_{0} 0.34-0.35 \mathrm{~g} \mathrm{~cm}^{-3}$; xenon: $V_{\text {cryst. }} 0.274 \mathrm{~g} \mathrm{~cm}^{-3}, V g_{0} 0.27 \mathrm{~g} \mathrm{~cm}^{-3}$; neon: $\left.V_{\text {cryst. }} 0.66 \mathrm{~g} \mathrm{~cm}^{-3}, V g_{0} 0.72-0.74 \mathrm{~g} \mathrm{~cm}^{-3}\right)$.

For non-spherical molecules, however, the difference between $T g_{0}$ and $T g_{l}$ is probably related to the ratio $A_{\text {Molmax }}$ to $A_{\text {Molmin }}$ (Figure 6).

\subsection{Influence of Mode Distribution Approaching $T g_{0}$}

Two very fundamental questions remain: which influences cause the fixing of a liquid structure when the cooling rate goes towards 0 , and does viscosity really get to infinity when approaching $T g_{0}$, as Figure $4 \mathrm{a}, \mathrm{b}$ implies? Which role does mode distribution play in this scenario?

This necessitates the examination of the influence of the vibration amplitudes in the transformation interval, as follows.

The vibrations of the vibrating elements are undoubtedly distributed around a mean value corresponding to the respective temperature. The width of the vibration amplitudes is limited and corresponds to a defined range of specific volumes $V i . V g_{0}$ represents the specific volume below which the apertures between molecules are smaller than the smallest molecular axis cross-sections. If, when approaching $V g_{0}$, the lowest $V_{i}$ values within a distribution are smaller than $V g_{0}$, the result is a state in which both liquid and glassy solid matter is present. This condition is basically present in the glass transition interval between $T g_{g}$ and $T g_{l i q}$. The relations in the transition interval are depicted in Figure 7.

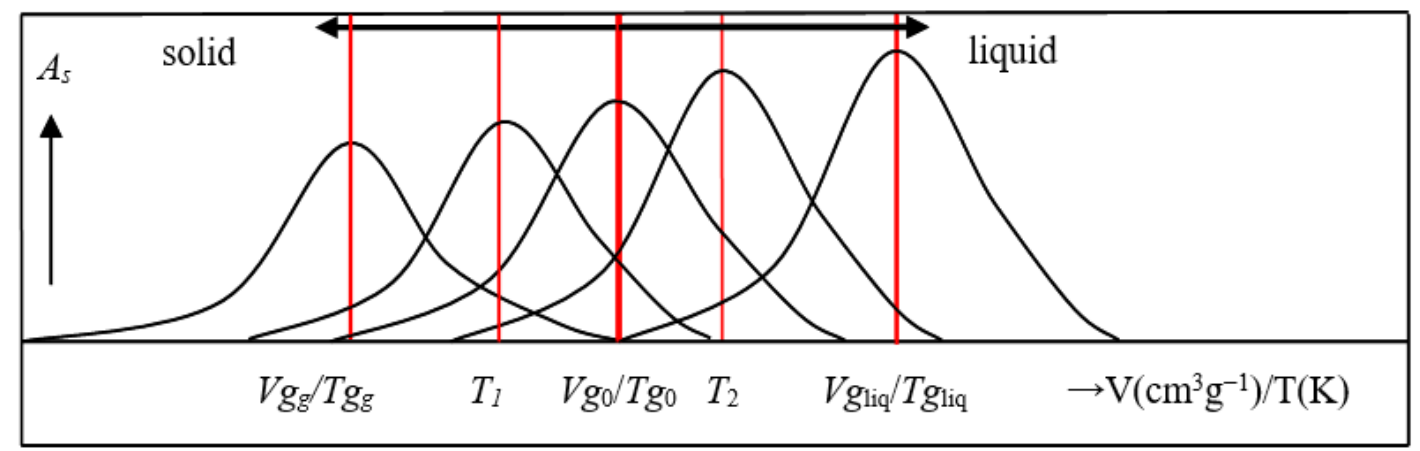

Figure 7. Influence of the vibration width at a chosen specific temperature (schematic). At $T g_{g}$ all vibration widths $V_{i}$ are smaller than $V g_{0}$. The solid state is given. When the temperature is raised to $T_{1}$, some $V_{i}$ exceed $V g_{0}$ and the total system consists of a solid matrix surrounding liquid droplets. At $T g_{0}$, about half of the total system (see section "Location of $T g_{0}$ in the transition interval") is solid and the other half liquid. At the temperature $T_{2}$, the system consists mainly of the liquid phase, which contains a proportion of solid particles. At $T g_{l i q}$ the system is pure liquid, because no single $V_{i}$ is lower than $V g_{0}$. ( $A_{s}$ are the vibration amplitudes). 
In the glass transition range the above relations are strongly time-dependent. Below $T g_{\text {liq }}$ more and more solid glassy matter is formed and it is assumed that there exists a suspension-like state. Decreasing the temperature further should create a state where the solid predominates and starts building a fixed structure with enclosed liquid droplets. When this status is reached, the reduction of the cooling rate can no longer influence the viscosity. That state should not be able to relax furthermore and $q T$ should not have any influence. That limiting $q T$ should be denoted $q T_{\min }$ (see also: Zondervan et al., 2008 [95]). Of course, when $q T<q T_{\text {min }}$ the included liquid droplets further on become smaller and smaller and can continue to relax, but this can no longer affect the entire system. Therefore, the viscosity should reach its maximum equilibrium value according to the relaxation time present at this point. In a paper from 2002 Krüger et al. [96] the authors, based on time domain Brillouin spectroscopy and hypersonic experiments, stated a cut off of the $\alpha$-relaxation at a temperature $T_{g S}$ and strongly hinted at the existence of an "isostructural" phase transition, however the transition mechanism was not elucidated. There is a certain probability that $T_{g s}$ is identical to the $T g_{g}$ of this work and the measurable $\alpha$-relaxation ends because the state "liquid droplets in a solid matrix" is reached.

\section{Identifying $T g_{0}$ from Measurements}

The determination of $T g_{0}$ from the $T g_{(q T)}$ values measured at a higher rate of temperature change is one of the key tasks of the problems associated with glass transition. There is a wealth of published work on both the theoretical basis and the detailed definition of the measured $T g$ values. An evaluation of the different measuring methods and definitions cannot be made by the author due to a lack of own experience and is also not the goal of this work. As an important result, however, it can be seen from the literature and it should be stressed that the $T g_{(q T)}$ values, even at the same cooling or heating rate, can be quite different.

Dilatometric and calorimetric measuring methods are common. Hutchinson [58] gives a very good overview and analysis. Obviously, there are experimental difficulties in achieving $T g_{(q T)}$ values. Dilatometry problems occur due to the deformability of the melt and as regards calorimetry mainly the problem of thermal lag in the samples causes difficulties. The calibration of the instruments also seems to be a source of uncertainty.

From the principle of physical simplicity, dilatometry should be the preferred method, but due to experimental manageability and the small sample quantities required DSC measurements have established themselves in practice. However, DSC measurements are not handled uniformly and the definition of the $T g$ value found in the literature varies. If the rate of temperature change is equal to or less than the reciprocal value of the structural equilibrium constant $\tau$, no deviation from the equilibrium density or enthalpy of the liquid should be obtained above $T g_{0}$. At $T g_{0}$, within an interval corresponding to the distribution width of the molecular vibrations, the equilibrium line is turned into the glass state.

The measurements can be carried out at equal or different heating or cooling rates, and thus the beginning and ending of the transition interval and the position of $\mathrm{Tg}$ in the interval can be defined diversely. There should be no question that the relationship between the heating rate and structural relaxation constant $\tau$, i.e., the distance to thermal equilibrium, determines the course of the examined property within the transition interval. The tangential inclination of the liquid side of the DSC transition step should be further on a function of the volume viscosity. The latter is very different for different substances at the same distance to $T g_{0}$, since it is very likely that the molecular packing density also determines this inclination and, subsequently, determines the position of the intersection of the two tangents. Regardless of the fundamental issues, this further restricts the physical significance of $T g_{(q T>0)}$.

Furthermore, it is very questionable that rate dependence can be calculated with one and the same equation for measurements with different definitions of $T g_{(q T)}$. In the best case scenario only the parameters of the equation are different, but it is quite likely that the 
general dependency is distinct. Therefore the determination of $T g_{0}$ from the $T g_{(q T)}$ data represents a major challenge.

Incidentally, the detected time dependence is not limited to Tg only. DSC measurements of crystalline matter show a temporal dependence of the same order for the start of crystallization [97] (Figure 3b there).

As the molecular vibrations are not uniform but distributed around a center value, the glass transition should not take place as singularity but in an interval. This should be valid independently from the preset cooling or heating rate, even for $q T \rightarrow 0$ (resp. $q T_{\min }$, see later).

From dilatometric measurements the earliest stage of the onset of the glass transformation $T g g$ may be taken as the temperature at which an initial alteration of the expansion coefficient in the glassy state starts. This should be independent of the amount of incorporated free volume, i.e., apply to all practical glasses, however at high rates of temperature change volume changes are difficult to detect.

The fact that in spite of different temperature changing rates the coefficients of volume expansion retain a constant value at a given characteristic temperature for the glass has been proven by studies of Bero and Plazek [98] on an epoxy resin. The phenomenon can, however, already be seen in former volume curves, e.g., by Ritland [29] for a BSC glass, Rötger [99] for the glass "Jena Normal 16 III", deBolt et al. [100] for $\mathrm{B}_{2} \mathrm{O}_{3}$, and Chen and Turnbull [73] for a gold-germanium-silicon-alloy.

Evaluations undertaken from the glass side are appropriate in measuring $T g_{0}$, as has also been confirmed by dielectric studies. For toluene, Döß et al. [101] have demonstrated that the dielectric constant independently from the used measuring frequencies always show a sharp kink at $T=117 \mathrm{~K}$, the same value as measured by DSC (as depicted in Figure 1 of that paper and [90]) and the calculated $T g_{0}$ value from viscosity measurements. Another impressive confirmation may be drawn from Figure 3 for a basaltic melt in Yue et al. [55].

If $T g$ is defined thermo-analytically (DTA, DSC), then $T g g$ is the temperature at which the basis line turns upward for the first time during the heating process. Although the heating method with heating rates greater than qTmin basically assumes a state outside the thermal equilibrium, the excess free volume does not prevent the generation of further vacancies. Exemplary measurement results are given for instance in Figure 3 for $\mathrm{CH}_{3} \mathrm{COO}\left(\mathrm{Li}_{0.86} \mathrm{Na}_{0.14}\right)\left(\mathrm{Tg}_{\mathrm{g}}\right.$ approximately $\left.360 \mathrm{~K}\right)$ and in Figure 6 for $\mathrm{GeO}_{2}\left(\mathrm{Tg}_{\mathrm{g}}\right.$ approximately $740 \mathrm{~K}$ ) in the study by Brüning and Crowell [102].

In the literature one often finds representations of $T g_{(q T)}$ as a straight line plotted over $\log (q T)$, and indeed with the usual $q T$ values, this relationship seems to be valid with many substances from different material classes.

$$
T g(q T)=T g_{(q T=1)}+\mathbf{u}^{*} \ln (|q T|)
$$

Exemplary results are shown by the dilatometric studies of Bero and Plazek [98] and the work of Brüning and Crowell [102] using the DSC results of LiNaAcetate and GeO2, as well as by Greiner and Schwarzl [103] and Hadač et al. [104] for polystyrene.

Such plots give the impression that there is no $T g_{0}$. However, the equation per se does not rule out that there is a cooling rate $q T_{\min }$, and that falling below this rate has an effect on the overall system. In the frame of the new model there should be definitely a lower bound of $T g_{(q T)}$ and a $q T_{\min }$ where the limit state is reached at which the transition from the status "solid particles in liquid medium" to "droplets in solid medium" takes place (see section "Influence of mode distribution approaching $T g_{0}$ ").

The surprising idea that a certain $q T_{\min }$ should exist was stated by Bero and Plazek [98] in their work of 1991:

"The data indicate that upon sufficiently slow cooling (ca. $2{ }^{\circ} \mathrm{C}$ per century) a sharp transition should be observed which could be thermodynamic in nature, since $T g$ would be independent of rate at all slower rates."

These authors state furthermore: 
"If the data correctly indicate bona fide evidence for a Tg-related thermodynamic transition, it does not seem likely that it is the $T_{\infty}$ suggested by a free volume analysis, or the $T_{2}$ of Gibbs, Adams, and Dimarzio, since the observed constant temperature of 118 is but $14{ }^{\circ} \mathrm{C}$ below the $T g$ obtained at a rate of cooling of $0.9^{\circ} \mathrm{C} / \mathrm{min}$. The values of $T_{\infty}$ and $T_{2}$ are usually thought to be some 30 to $60^{\circ} \mathrm{C}$ below the nominal $\mathrm{Tg}$ obtained at about a $1{ }^{\circ} \mathrm{C} / \mathrm{min}$ rate of cooling."

The dilatometric results of an epoxy resin examined by Bero and Plazek [98] listed in Table 1 are very interesting because they were obtained at very low cooling rates. Therefore, they should be analyzed in more detail.

Table 1. Dilatometric results for Epon 1001f-DDS.

\begin{tabular}{cc}
\hline $\boldsymbol{q T}(\mathrm{K} / \mathbf{m i n})$ & $\boldsymbol{T g}_{\boldsymbol{i}}(\mathrm{K})$ \\
\hline 0.9 & 131.7 \\
0.25 & 130.5 \\
0.05 & 128.9 \\
0.003 & 126.1 \\
\hline
\end{tabular}

Depending on the cooling rate $q T_{i}$, the following $T g_{i}$ values were measured:

The first deviation from the expansion coefficient of the glass was detected above $T g_{g}=118 \mathrm{~K}$.

Using Equation (2) the following equation parameters are obtained: $T g_{(q T=1 \mathrm{~K} / \mathrm{min})}=$ $131.83 \mathrm{~K} ; \mathrm{u}=0.9847$. See Table 1 .

If Table 1 is extended with $T g_{g}$ and the standard deviation is determined as a function of an arbitrarily assumed effective minimum cooling rate at $118 \mathrm{~K}$, the following regression results are obtained (Table 2):

Table 2. Evolution of standard deviation for Epon 1001f-DDS with arbitrarily chosen $q T_{\min }$ at $118 \mathrm{~K}$.

\begin{tabular}{cccccccc}
\hline $\begin{array}{c}q T_{\min } \\
(\mathbf{K} / \mathbf{m i n})\end{array}$ & $\begin{array}{c}\sigma(T g) \\
(\mathbf{K})\end{array}$ & $\begin{array}{c}q T_{\min } \\
(\mathbf{K} / \mathbf{m i n})\end{array}$ & $\begin{array}{c}\sigma(T g) \\
(\mathbf{K})\end{array}$ & $\begin{array}{c}q T_{\min } \\
(\mathbf{K} / \mathbf{m i n})\end{array}$ & $\begin{array}{c}\sigma(T g) \\
(\mathbf{K})\end{array}$ & $\begin{array}{c}q T_{\min } \\
(\mathbf{K} / \mathbf{m i n})\end{array}$ & $\begin{array}{c}\sigma(T g) \\
(\mathbf{K})\end{array}$ \\
\hline $1 \times 10^{-9}$ & 0.86 & $1 \times 10^{-6}$ & 0.054 & $7.95 \times 10^{-7}$ & 0.0278 & $5 \times 10^{-7}$ & 0.091 \\
\hline $1 \times 10^{-8}$ & 0.64 & $9 \times 10^{-7}$ & 0.038 & $7.5 \times 10^{-7}$ & 0.0297 & $1 \times 10^{-5}$ & 0.607 \\
\hline $1 \times 10^{-7}$ & 0.35 & $8 \times 10^{-7}$ & 0.028 & $7 \times 10^{-7}$ & 0.037 & \\
\hline
\end{tabular}

Figure 8 shows the steep but finite increase in the gradient of $\operatorname{Tg}(q T)$ at very slow temperature changes.

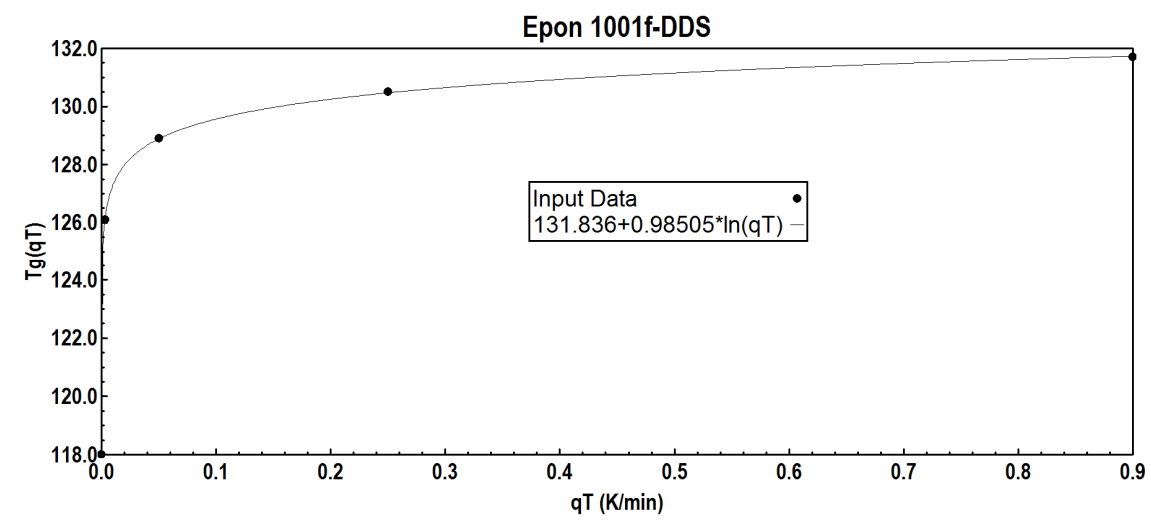

Figure 8. Development of $T g_{(q T)}$ with $q T_{\min }=7.95 \times 10^{-7}\left(\mathrm{r}^{2}=0.999981 ; \sigma=0.028 \mathrm{~K} ; \Delta_{\max }=0.032 \mathrm{~K}\right)$.

An interesting result offers the comparison of the $q T_{\min }$ parameter for EP with the stated values of Bero and Plazek: $2 \mathrm{~K} /$ century $=3.8 \times 10^{-8} \mathrm{~K} / \mathrm{min}$ versus $7.9 \times 10^{-7} \mathrm{~K} / \mathrm{min}$. 
Bero and Plazek gave no derivation for the stated value but it can be supposed that it is surely not pure invention. In any case, it is a remarkable agreement.

According to the new model presuming a fixed $T g_{0}$, the function must be curved in a semilogarithmic plot. Furthermore, there must be a $q T_{\min }$ at which a further slowing down of the cooling rate has no effect anymore, because the state "liquid droplets in solid environment" is reached.

Figure 9 shows the basic conditions.

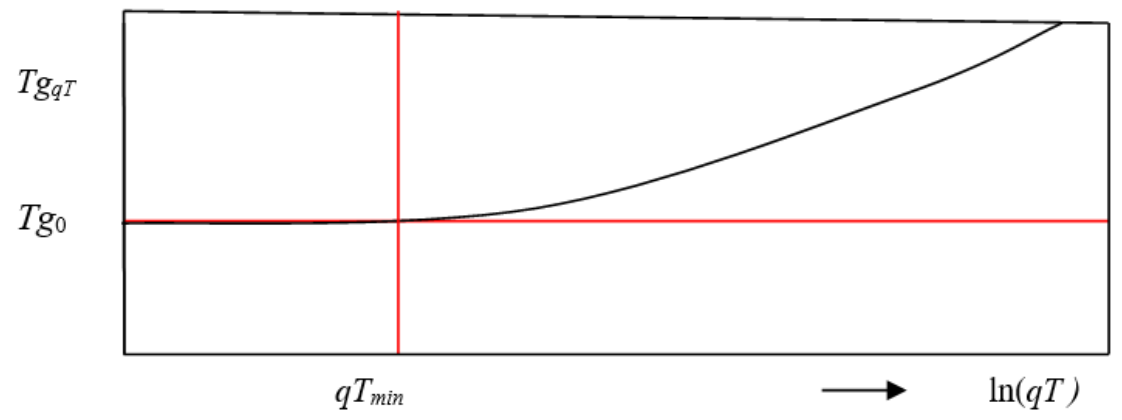

Figure 9. $T g=\mathrm{f}(q T))$ (schematic).

In 1991 Brüning and Samwer [46] carried out DSC measurements on metallic glasses, $\mathrm{B}_{2} \mathrm{O}_{3}$, and polymers with very slow rates of temperature change and suspected a temperature $T_{g}{ }^{0}$ as "lower limit of $T g$ " due to the deflection of the function $T g=f(\ln (q T))$. They measured $T g$ as the onset of the $\Delta C p$ peak on heating at the point of intersection between the linearly extrapolated curve below the transition with the steepest tangent of the rise in $\Delta C p$, making the important remark that "it is apparent that the extension of the measurements to low heating rates is necessary to observe the deviation from a straight line in the semilogarithmic plot."

They gave an equation for the dependence of $T g$ from $q T$ :

$$
T g(q T)=T g^{0}+A / \ln (B / q T)
$$

whereby $\operatorname{Tg}(q T)$ is defined as the onset of the $T g$ step.

The theoretical consequences of the experimental findings of Brüning and Samwer concerning the fundamental questions of the glass transition do not seem to have been considered further in the subsequent period, or only very rarely. In 2015 Schawe [105] published a paper containing measurements on polystyrene with very slow and very fast $q T$ values using a new type of DSC equipment. $T g$ was defined by the equal area method [106,107] as a mid-step value and the VFT form was used for calculating $q T$ dependence. The experiments confirm the logical consequence of the presented model that there must be a lower limit of $T g$, here denoted as $T g g_{0}$.

Table 3 shows the used substances, $q T$ and $T g_{(q T)}$, whereby the data are extracted from the graphic of Figure 5 by Brüning and Samwer and from Figure 6 by Schawe.

Table 3. Measured $\operatorname{Tg}(q T)$ values.

\begin{tabular}{|c|c|c|c|c|c|c|c|c|c|c|c|c|c|c|c|c|}
\hline Rate & $\begin{array}{l}\mathbf{B}_{2} \mathrm{O}_{3} \\
{[46]}\end{array}$ & $\begin{array}{c}\mathbf{P d}_{40} \mathrm{Ni}_{59} \mathbf{P}_{19} \mathrm{Si}_{1} \\
{[46]}\end{array}$ & PMM & A [46] & & & & & & olystyre & le [107] & & & & & \\
\hline $\begin{array}{c}q T \\
(\mathrm{~K} / \mathrm{min})\end{array}$ & $T g_{(q T)}$ & $T g_{(q T)}$ & $\begin{array}{c}q T \\
(\mathrm{~K} / \mathrm{min})\end{array}$ & $T g_{(q T)}$ & $\begin{array}{c}q T \\
(\mathrm{~K} / \mathrm{s})\end{array}$ & $T g_{(q T)}$ & $\begin{array}{c}q T \\
(\mathrm{~K} / \mathrm{s})\end{array}$ & $T g_{(q T)}$ & $\begin{array}{c}q T \\
(\mathrm{~K} / \mathrm{s})\end{array}$ & $T g_{(q T)}$ & $\begin{array}{c}q T \\
(\mathrm{~K} / \mathrm{s})\end{array}$ & $T g_{(q T)}$ & $\begin{array}{c}q T \\
(\mathrm{~K} / \mathrm{s})\end{array}$ & $T g_{(q T)}$ & $\begin{array}{c}q T \\
(\mathrm{~K} / \mathrm{s})\end{array}$ & $T g_{(q T)}$ \\
\hline 0.1 & 538.6 & 554.6 & 0.1 & 378.1 & 0.0033 & 368.8 & 0.5 & 374.2 & 5 & 478.3 & 100 & 381.5 & 700 & 386.8 & 3000 & 390 \\
\hline 0.2 & 540 & 555.7 & 0.2 & 377.8 & 0.008 & 369.2 & 0.5 & 375 & 10 & 377.3 & 100 & 382.3 & 700 & 387.5 & 3000 & 390.5 \\
\hline 0.5 & 544.5 & 560.0 & 0.5 & 378.5 & 0.016 & 370.6 & 0.65 & 374 & 10 & 378.6 & 100 & 382.5 & 800 & 385.4 & 3000 & 391 \\
\hline 1.0 & 547.4 & 561.9 & 1.0 & 378.5 & 0.033 & 370.7 & 0.83 & 373.8 & 10 & 379.3 & 200 & 383.2 & 800 & 387 & 4000 & 391.3 \\
\hline 2.0 & 553.8 & 565.1 & 2.0 & 380.3 & 0.05 & 371.5 & 0.83 & 374.5 & 20 & 379 & 200 & 384 & 800 & 388 & 4000 & 391.5 \\
\hline
\end{tabular}


Table 3. Cont.

\begin{tabular}{|c|c|c|c|c|c|c|c|c|c|c|c|c|c|c|c|c|}
\hline \multirow{2}{*}{$\begin{array}{c}\text { Rate } \\
\begin{array}{c}q T \\
(\mathrm{~K} / \mathrm{min})\end{array}\end{array}$} & \multirow{2}{*}{$\begin{array}{l}\mathrm{B}_{2} \mathrm{O}_{3} \\
{[46]} \\
T g_{(q T)}\end{array}$} & \multirow{2}{*}{$\begin{array}{c}\mathrm{Pd}_{40} \mathrm{Ni}_{59]} \mathrm{P}_{19} \mathrm{Si}_{1} \\
\left.\mathrm{Tg}_{(q T} \mathrm{T}\right)\end{array}$} & \multicolumn{2}{|c|}{ PMMA [46] } & \multicolumn{12}{|c|}{ Polystyrene [107] } \\
\hline & & & $\begin{array}{c}q T \\
(\mathrm{~K} / \mathrm{min})\end{array}$ & $T g_{(q T)}$ & $\begin{array}{c}q T \\
(\mathrm{~K} / \mathrm{s})\end{array}$ & $T g_{(q T)}$ & $\begin{array}{c}q T \\
(\mathrm{~K} / \mathrm{s})\end{array}$ & $T g_{(q T)}$ & $\begin{array}{c}q T \\
(\mathrm{~K} / \mathrm{s})\end{array}$ & $T g_{(q T)}$ & $\begin{array}{c}q T \\
(\mathrm{~K} / \mathrm{s})\end{array}$ & $T g_{(q T)}$ & $\begin{array}{c}q T \\
(\mathrm{~K} / \mathrm{s})\end{array}$ & $T g_{(q T)}$ & $\begin{array}{c}q T \\
(\mathrm{~K} / \mathrm{s})\end{array}$ & $T g_{(q T)}$ \\
\hline 5.0 & 555.8 & 567.5 & 5.0 & 381.1 & 0.08 & 372 & 1 & 375.5 & 20 & 379.8 & 200 & 385 & 1000 & 387 & 5000 & 392 \\
\hline 10.0 & 566.8 & 571.8 & 5.0 & 381.8 & 0.1 & 372 & 1 & 375.2 & 20 & 381 & 200 & 385.8 & 1000 & 388 & & \\
\hline 20.0 & 571.2 & 576.7 & 10 & 382.5 & 0.1 & 373 & 2 & 375.8 & 50 & 380 & 500 & 384 & 1000 & 388 & & \\
\hline 50.0 & 574.9 & 581.2 & 10 & 383.2 & 0.17 & 372.5 & 2 & 376.9 & 50 & 380.8 & 500 & 386 & 2000 & 389 & & \\
\hline 100.0 & 589.7 & 586.9 & 20 & 385.1 & 0.2 & 373.6 & 2 & 378.5 & 50 & 382 & 500 & 387 & 2000 & 390 & & \\
\hline \multirow[t]{3}{*}{200.0} & 602.5 & 595.0 & 20 & 385.8 & 0.33 & 373 & 5 & 377.6 & 50 & 382.6 & 700 & 385.5 & 2000 & 390.5 & & \\
\hline & & & 50 & 386.0 & & & & & & & & & & & & \\
\hline & & & 100 & 388.0 & & & & & & & & & & & & \\
\hline
\end{tabular}

To determine whether there is a functional relationship, regression analyses were performed with the following equations which are listed in Table 4.

Table 4. Equations used.

\begin{tabular}{ccc}
\hline Equations & Name & Formula \\
\hline 1 & Brüning-Samwer & $T g(q T)=T_{0}+\mathrm{a} / \ln (\mathrm{B} / q T)$ \\
\hline 2 & Yue-invers [55] & $T g(q T)=T g /((-\ln (\mathrm{x})-\mathrm{a}) / \mathrm{b})^{\mathrm{k}}$ \\
\hline 3 & GS-1 ${ }^{\mathrm{a}}$ & $T g(q T)=T g_{0}+\left(q T / q T_{\min }\right)^{\mathrm{b}}$ \\
\hline 4 & $\mathrm{GS}^{\mathrm{a}}$ & $T g(q T)=T g_{0} /\left(1-\left(q T^{*} q T_{\text {min }}\right)^{\mathrm{b}}\right)$ \\
\hline 5 & Bartenew-Ritland & $T g(q T)=1 /\left(\mathrm{a}-\mathrm{b}^{*} \ln (q T)\right)$ \\
\hline 6 & $\operatorname{lin}-\log$ (Equation $(2))$ & $T g(q T)=T g_{(q T=1)}+\mathrm{u}^{*} \ln (q T)$ \\
\hline
\end{tabular}

a This work. Equations GS-1 and GS-2 were developed with the goal of keeping Tg constant below $q T_{\min }$ as required by the model. Mathematical functions were sought that led to this result.

The results for $\mathrm{B} 2 \mathrm{O} 3$ are given in Table 5.

Table 5. Regression results for $\mathrm{B}_{2} \mathrm{O}_{3}$.

\begin{tabular}{|c|c|c|c|c|c|c|c|c|c|c|c|c|}
\hline \multirow[b]{3}{*}{ Equation } & \multicolumn{12}{|c|}{ Results for } \\
\hline & \multicolumn{6}{|c|}{$\mathrm{B}_{2} \mathrm{O}_{3}$ (All Data) } & \multicolumn{6}{|c|}{$\mathrm{B}_{2} \mathrm{O}_{3}$ (Without $\left.q T=50 \mathrm{~K} / \mathrm{s}\right)$} \\
\hline & $\begin{array}{c}\sigma \\
(\mathrm{K})\end{array}$ & $\mathbf{R}^{2}$ & $\begin{array}{c}T g_{0} / T_{0} \\
\text { (K) }\end{array}$ & $a,\left(q T_{\min }\right)$ & $b / B / u$ & $k$ & $\begin{array}{c}\sigma \\
(\mathrm{K})\end{array}$ & $\mathbf{R}^{2}$ & $\begin{array}{c}T g_{0} / T_{0} \\
\text { (K) }\end{array}$ & $a,\left(q T_{\min }\right)$ & $b / B / u$ & $k$ \\
\hline Yue-invers & 2.52 & 0.990 & 496.4 & -7.0917 & 30.65 & 0.0680 & 1.86 & 0.995 & 499.7 & -7.596 & 25.028 & 0.0783 \\
\hline Brüning-Samwer & 2.46 & 0.989 & 492.5 & 601.42 & $49,719.5$ & & 1.67 & 0.995 & 483.3 & 760.94 & 120,613 & \\
\hline GS-1 & 2.60 & 0.988 & 525.8 & $1.58 \times 10^{-6}$ & 0.2314 & & 1.65 & 0.995 & 522.2 & $2.186 \times 10^{-7}$ & 0.2122 & \\
\hline GS-2 & 2.56 & 0.988 & 523.6 & $1.91 \times 10^{-7}$ & 0.2016 & & 1.65 & 0.995 & 519.3 & $8.697 \times 10^{-8}$ & 0.1812 & \\
\hline Bartenew-Ritland & 2.75 & 0.948 & - & 0.0018 & $2.5 \times 10^{-5}$ & & 4.68 & 0.958 & & 0.0018 & $2.63 \times 10^{-5}$ & \\
\hline lin-log (Equation (2)) & 5.82 & 0.930 & $(550.0)$ & - & 7.822 & & 6.37 & 0.945 & $(550.4)$ & 8.209 & & \\
\hline
\end{tabular}

Red characters prob(t) fails.

The calculated $T g_{0}$ values of equations GS-1 and GS-2 are nearly similar to the values found with viscosity [108], where it can be assumed that the water content of the measured samples is low $(<0.1 \%)$ but not identical.

The equations Brüning and Samwer and Yue-invers do not reach a constant value even at a $q T$ of $10^{-40} \mathrm{~K} / \mathrm{min}$, whereas with equation GS- 1 the Tg value decreases by a maximum of $1 \mathrm{~K}$ when $q T$ values below $q T_{\min }$ are chosen. Interestingly $q T_{\min }$ again has an order of magnitude of around $10^{-7} \mathrm{~K} / \mathrm{min}$.

Figure 10 shows the predicted course of the functions $T g=f(q T)$ for very low cooling rates. 


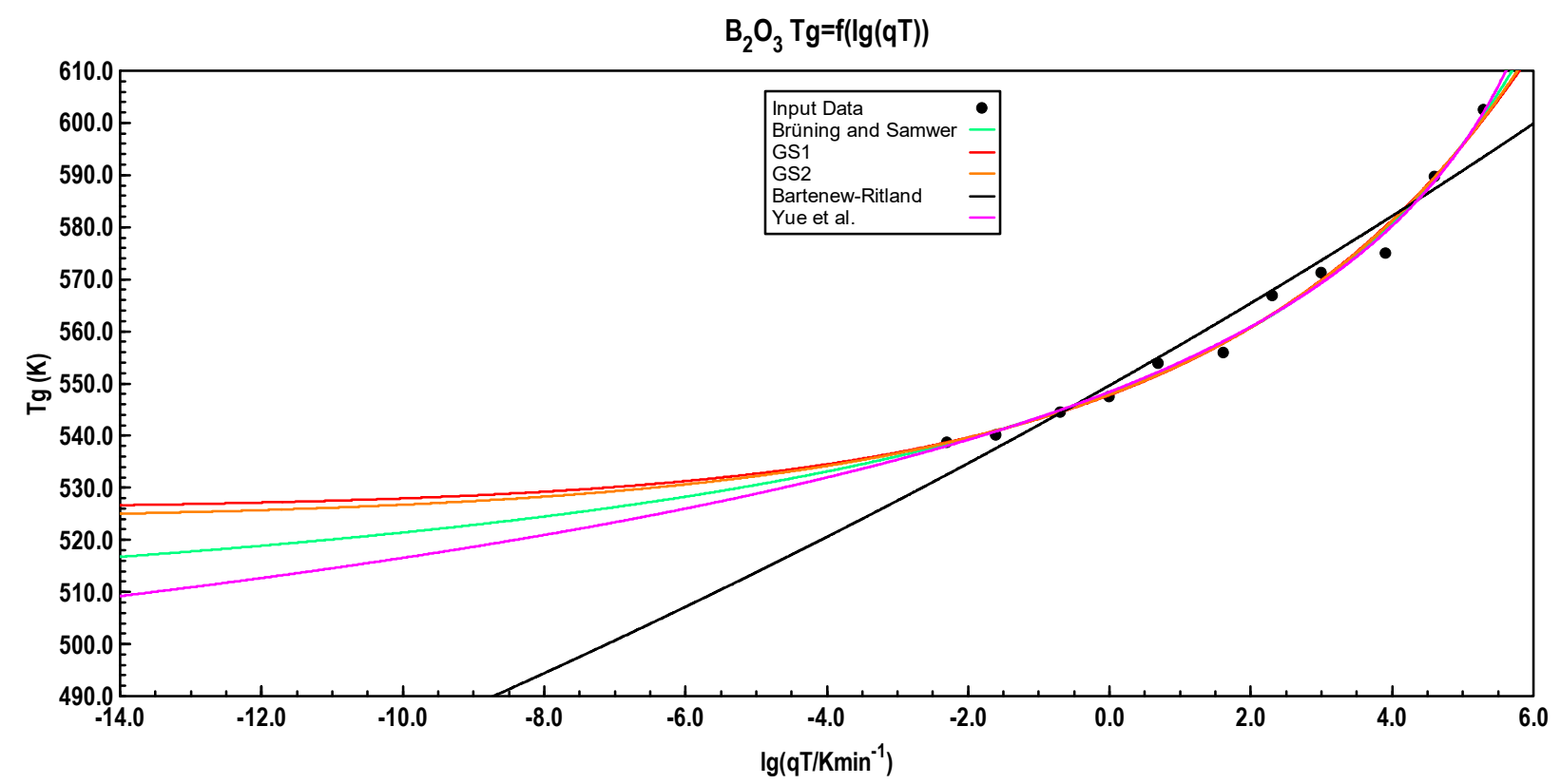

Figure 10. $\mathrm{B}_{2} \mathrm{O}_{3}$ : behavior of equations to determine $T g_{0}$.

The results for two metallic alloys are listed in Table 6 below.

Table 6. Regression results for $\mathrm{Pd}_{40} \mathrm{Ni}_{40} \mathrm{P}_{19} \mathrm{Si}_{1}$ and $\mathrm{La}_{55} \mathrm{Al}_{25} \mathrm{Ni}_{20}$.

\begin{tabular}{|c|c|c|c|c|c|c|c|c|c|c|c|c|}
\hline \multirow[b]{2}{*}{ Equations } & \multicolumn{6}{|c|}{$\mathrm{Pd}_{40} \mathrm{Ni}_{40} \mathrm{P}_{19} \mathrm{Si}_{1}$} & \multicolumn{6}{|c|}{$\mathrm{La}_{55} \mathrm{Al}_{25} \mathrm{Ni}_{20}$ (Without Highest qT) } \\
\hline & $\begin{array}{c}\sigma \\
(\mathrm{K})\end{array}$ & $\mathbf{R}^{2}$ & $\begin{array}{l}T g_{0} / T_{0} \\
\text { (K) }\end{array}$ & $a_{,}\left(q T_{\min }\right)$ & $b / B$ & $k$ & $\sigma(K)$ & $\mathbf{R}^{2}$ & $\begin{array}{c}T g_{0} / T_{0} \\
\text { (K) }\end{array}$ & $a,\left(q T_{\min }\right)$ & $b / B$ & $k$ \\
\hline Yue-invers & 0.72 & 0.998 & 591.2 & -7.3620 & 2.3605 & 0.0451 & 1.24 & 0.992 & 356.2 & -9.74 & 18.02 & 0.1143 \\
\hline Brüning-Samwer & 0.81 & 0.997 & 522.5 & 451.65 & 106,262 & & 1.13 & 0.992 & 308.2 & 1214.0 & 135,785 & \\
\hline GS-1 & 0.98 & 0.996 & 545.4 & $1.90 \times 10^{-6}$ & 0.2103 & & 1.14 & 0.992 & 347.4 & $1.59 \times 10^{-12}$ & 0.1305 & \\
\hline GS-2 & 0.95 & 0.996 & 544.4 & $1.22 \times 10^{-8}$ & 0.1919 & & 1.14 & 0.992 & 343.9 & $2.82 \times 10^{-10}$ & 0.1037 & \\
\hline Bartenew-Ritland & 2.6 & 0.964 & - & 0.0018 & $1.6 \times 10^{-5}$ & & 1.51 & 0.984 & & 0.0026 & $3.45 \times 10^{-5}$ & \\
\hline
\end{tabular}

Red characters prob(t) fails.

The predicted course of $T g(q T)$ for $\mathrm{Pd}_{40} \mathrm{Ni}_{40} \mathrm{P}_{19} \mathrm{Si}_{1}$ with the above tabulated equations is shown in Figure 11.

Additionally, with the metal alloy $\mathrm{Pd}_{40} \mathrm{Ni}_{40} \mathrm{P}_{19} \mathrm{Si}_{1}$, equations GS-1 and GS-2 again give a $q T_{\min }$ of the order $10^{-7} \mathrm{~K} / \mathrm{min}$.

The results for two measured polymers are listed in Table 7.

The data scatter with PMMA seems to be too strong for a reliable regression analysis. Nevertheless, the result for equation GS-1 yields the expected $T g_{0}$. The predicted course calculated with the equations is shown in Figure 12.

As mentioned, Schawe uses a different definition for the measured $\operatorname{Tg}(q T)$ values. Therefore it is questionable if the same equations can be applied. The qualitative picture shown in Figure 13 offers a rather similar behavior in respect to the other investigated materials, however the constant value for $T g$ with equations GS-1 and GS-2 is achieved at somewhat lower cooling rates. The calculated $T g_{0}$ values are very plausible and match well the viscosity-based values, where equation GS-1 may be preferable because of its simple mathematical structure. 


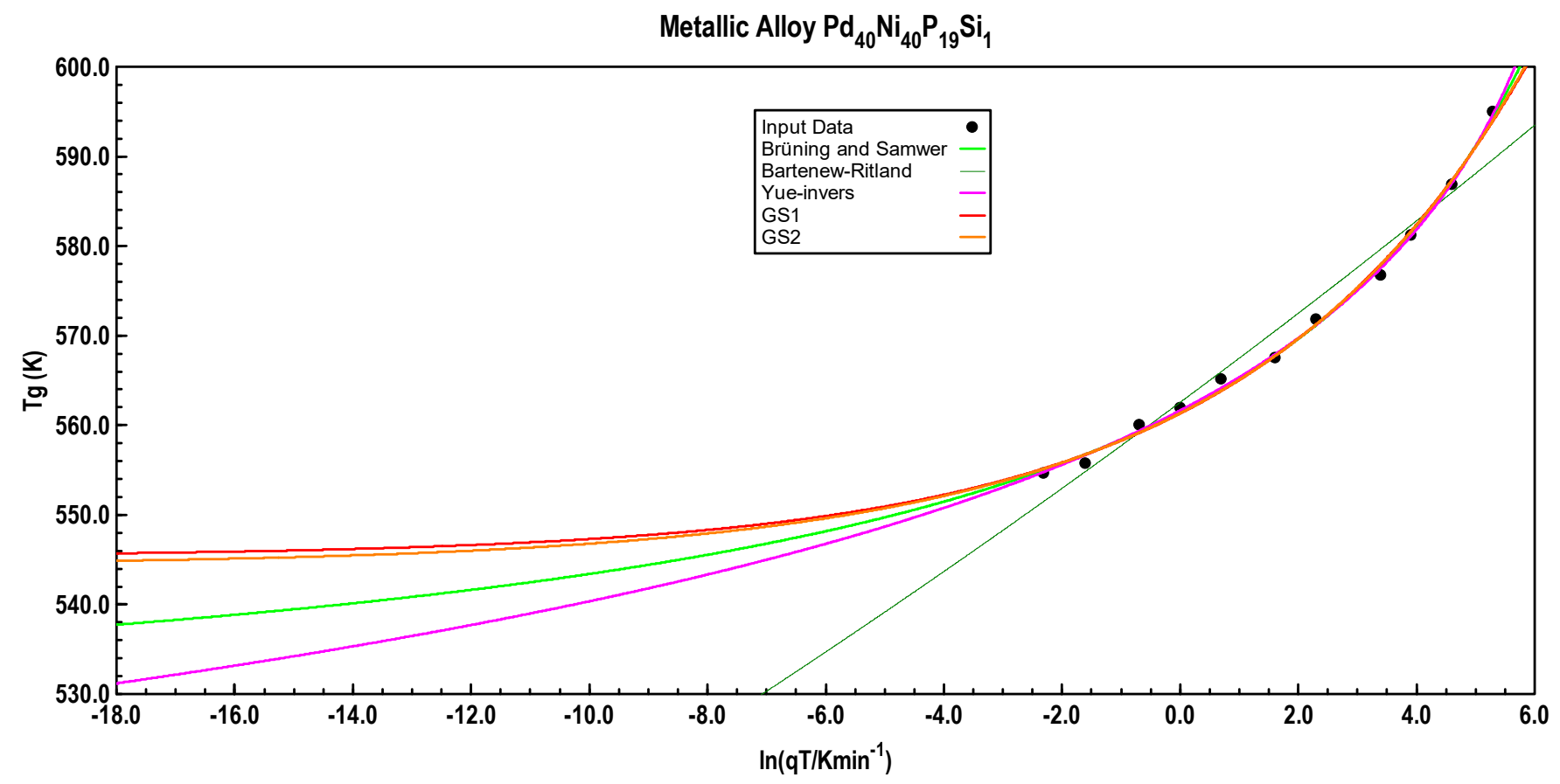

Figure 11. Predicted course of $T g(q T)$ for $\mathrm{Pd}_{40} \mathrm{Ni}_{40} \mathrm{P}_{19} \mathrm{Si}_{1}$.

Table 7. Regression results for the high polymers PMMA and PS.

\begin{tabular}{|c|c|c|c|c|c|c|c|c|c|c|c|c|}
\hline \multirow[b]{3}{*}{ Equation } & \multicolumn{12}{|c|}{ Results for } \\
\hline & \multicolumn{6}{|c|}{ PMMA } & \multicolumn{6}{|c|}{ Polystyrene (Mw 270,000; Mn 95,000 g/mol) } \\
\hline & $\begin{array}{c}\sigma \\
(\mathbf{K})\end{array}$ & $\mathbf{R}^{2}$ & $\begin{array}{c}T g_{0} / T_{0} \\
\text { (K) }\end{array}$ & $a,\left(q T_{\min }\right)$ & $b / B / u$ & $k$ & $\begin{array}{c}\sigma \\
(\mathbf{K})\end{array}$ & $\mathbf{R}^{2}$ & $\begin{array}{c}T g_{0} / T_{0} \\
\text { (K) }\end{array}$ & $a,\left(q T_{\min }\right)$ & $b / B / u$ & $k$ \\
\hline GS-1 & 0.74 & 0.961 & 373.5 & $1.17 \times 10^{-4}$ & 0.1979 & & 0.78 & 0.987 & 358.7 & $1.4 \times 10^{-13}$ & 0.083 & \\
\hline GS-2 & 0.74 & 0.960 & 373.3 & $3.32 \times 10^{-10}$ & 0.1885 & & 0.78 & 0.987 & 357.5 & $1.6 \times 10^{-20}$ & 0.074 & \\
\hline Brüning-Samwer & 0.77 & 0.958 & 364.2 & 192.56 & 292,795 & & 0.78 & 0.987 & 338.8 & 974.2 & $2.8 \times 10^{13}$ & \\
\hline Yue-invers & 0.83 & 0.955 & 373.6 & -7.814 & 14.60 & 0.026 & 0.78 & 0.987 & 340.6 & -19.93 & 86.17 & 0.057 \\
\hline Bartenew-Ritland & 1.0 & 0.920 & - & 0.00263 & $1.068 \times 10^{-5}$ & & 1.14 & 0.972 & - & 0.0027 & $1.2 \times 10^{-5}$ & \\
\hline $\operatorname{lin}-\log$ & 0.71 & 0.947 & $(379.9)$ & - & 1.549 & & 1.22 & 0.968 & $(368.8)$ & - & 1.687 & \\
\hline
\end{tabular}

Red characters prob(t) fails.

The calculations are strongly influenced by the data scatter and more data with slower cooling rates are urgently needed for a final decision, both on the extension to very slow cooling rates and on the number of substances. This also applies to dilatometric or volumetric data, which are of interest by the principle of thermo-physical simplicity.

Nevertheless, the equations providing a constant $T g$ value at not too low $q T$ values are a strong confirmation of the presented physical model predicting a lower limit of $\operatorname{Tg}(q T)$ at $q T_{\min }$. 


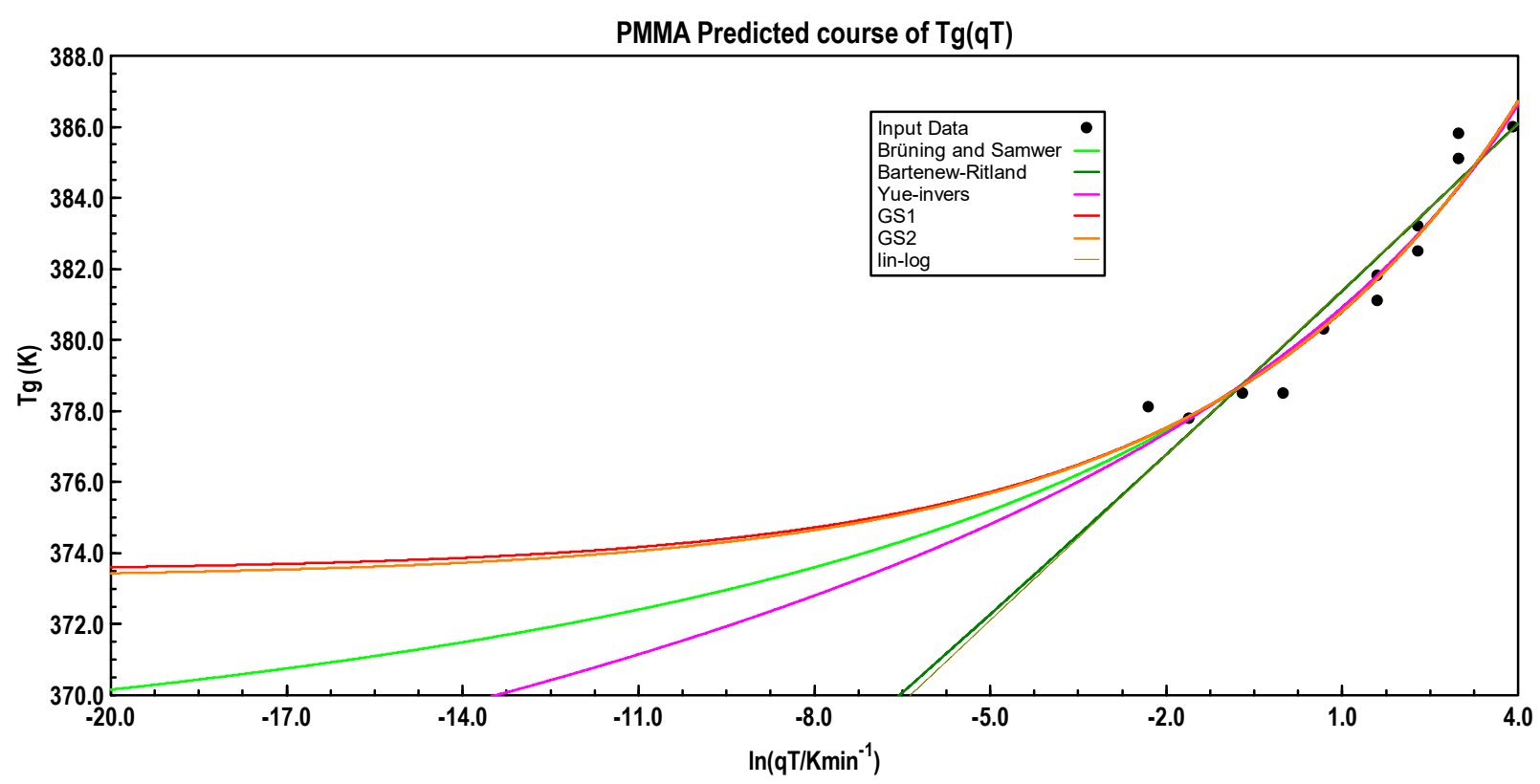

Figure 12. Predicted course of $T g=f(q T)$ for PMMA.

The results of Schawe for PS are depicted in Figure 13.

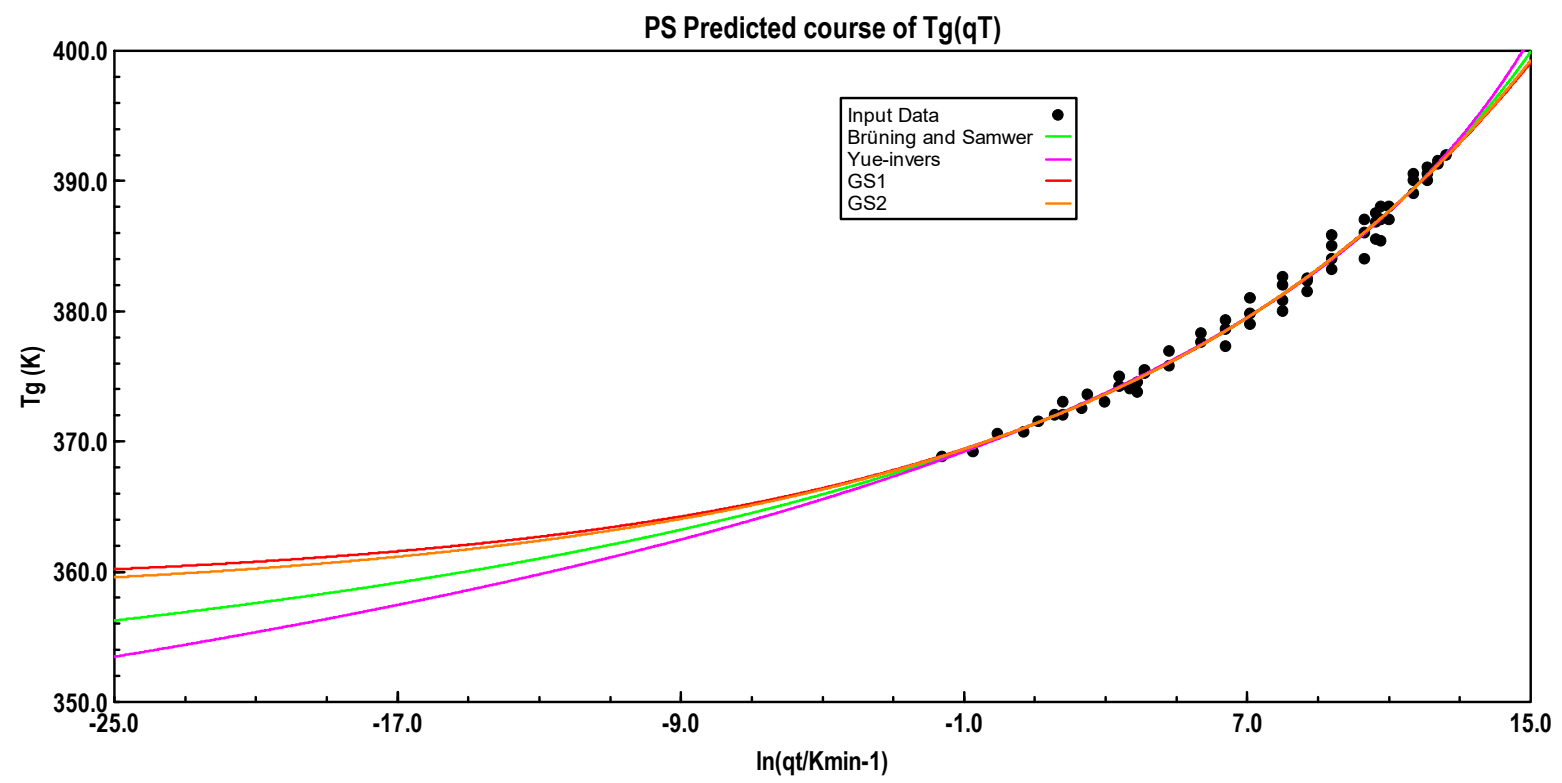

Figure 13. Polystyrene: behavior of equations to determine $T g_{0}$.

\section{Location of $T g_{0}$ in the Transition Interval}

Another interesting question refers to the limits and mean values of mode distribution in the transition interval. In the study of Holubová et al. [109] the step scan-DSC technique was applied. The authors point out that the ascertained $\mathrm{Tg}$ values are independent from the thermal history and the rate of temperature change. The transformation intervals were determined for various substances with $\mathrm{Tg}$ values in between $23^{\circ} \mathrm{C}$ and $507^{\circ} \mathrm{C}$. The authors concluded from the gathered data that the glass transition cannot be seen as a pure kinetic process. They propose to define the inflection point determined by the step scan-DSC technique as clear material specific glass temperature. 
It should be noted, however, that the step scan technique has its limitations when approaching $T g_{0}$, since the waiting times increase exponentially and are difficult to maintain experimentally.

If one presupposes that real matters show vibration distributions around a medium value, the $C p$ step, as set out above, has to cover a temperature interval even when the cooling rate decreases towards 0 . Consequently, the selection of the inflection point within the interval seems to be absolutely reasonable. At normal DSC measurements this inflection point is, however, not visible as it is covered up by the time-dependent enthalpy modifications. In this case, it remains reasonable to define the first deviation from the basis line as $T g_{g}$.

In a study from 2003 by Holubová et al. [110] the inflection point $T_{\mathrm{i}}$ was fixed at 0.632 of the entire interval width. In a later study (Chromčíková et al. [110]) the position of the inflection point was stated as $0.5-\mathrm{R} T_{\mathrm{i}} / \Delta H$. If one considers the vibration distributions to be deemed qualitatively possible for the limit temperatures of both states, and if one supposes that the distribution width is in proportion to the respective temperature, it may be suggested that the inflection point is situated in the lower interval region close to the center value in accordance with the above-mentioned study. In the second part of this thesis it will be shown that the best results of the calculation of viscosity when approaching the glass transition interval are obtained when $\Omega=\mathrm{e}^{-\Omega}=0.56714$ is selected as the inflection point. By choosing $\Omega$, the viscosity reaches its maximum value and $\mathrm{d} \eta / \mathrm{d} T$ becomes 0 .

Finally, it should be pointed out that the width of the transition interval can differ greatly across the different substance classes. If one puts the distribution of the vibration amplitudes in proportion with the width of the density fluctuation, the relation between the limiting and the main temperatures is well clarified as shown in Figure 14.

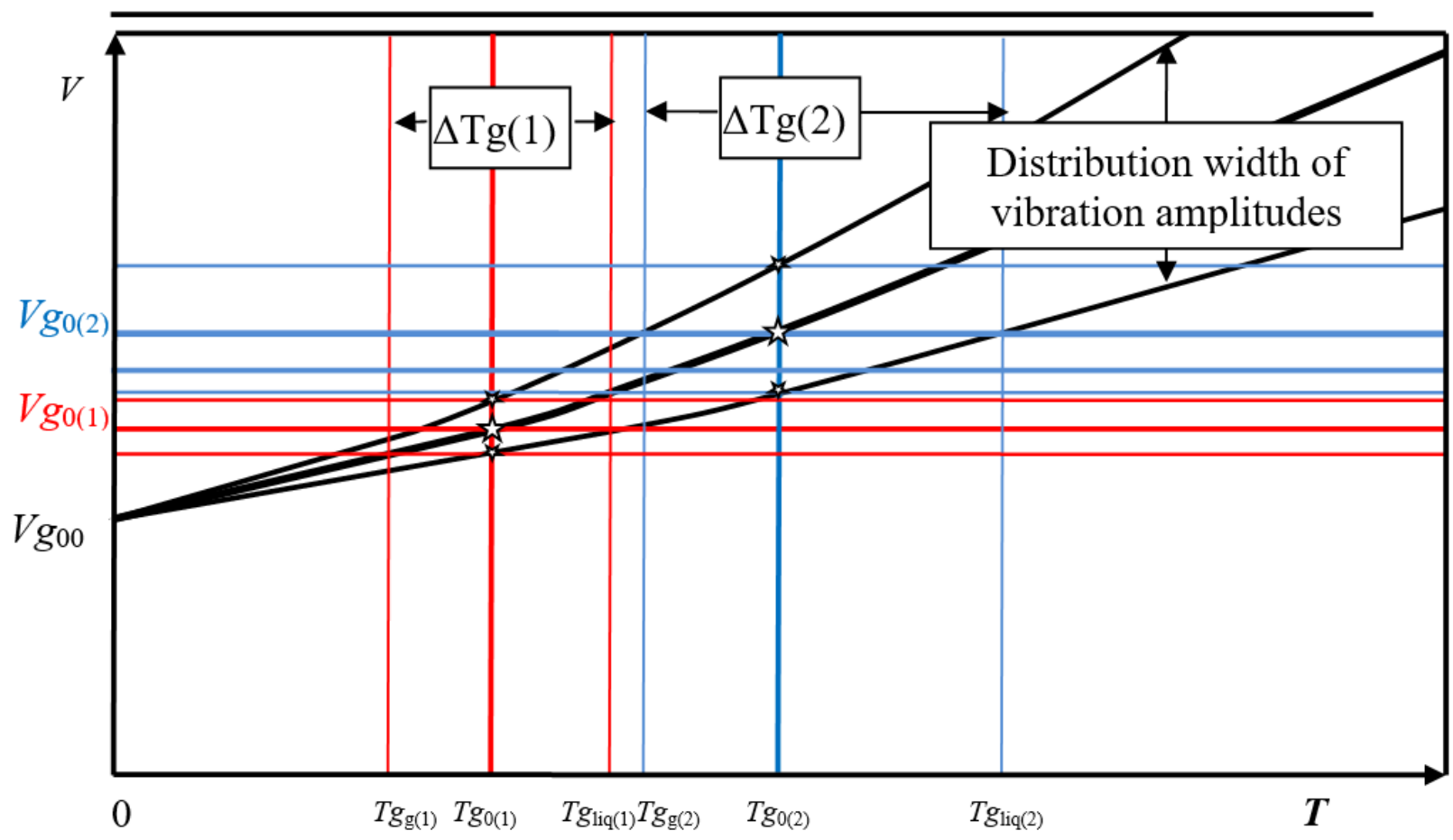

Figure 14. Width of the transformation interval in dependence of the magnitude of $T g_{0}$ (schematic). Comparison of two different substances. The crucial quantity is $V g_{0}$ since it is connected with molecule size and geometry. The width of the glass transition is denoted as $\Delta T g$. 
From Figure 14 a feature of highly practical importance may be deduced. The width of the transformation interval depends strongly on $T g_{0}$ itself, roughly as a rule of thumb about $0.1 \mathrm{Tg}_{0}$, but there are large deviations (for example anorthite $0.09, \mathrm{~B}_{2} \mathrm{O}_{3} 0.1, \mathrm{SiO}_{2} 0.18$, $\mathrm{GeO}_{2} 0.18$, Ca 0.390 .06 , 6-Phenylether 0.06 , see part II), presumably caused by different packing densities. Specifically in the case of silicate glasses softening may start at more than $100 \mathrm{~K}$ lower than the conventional measured $T g_{(q T=10 \mathrm{~K} / \mathrm{min})}$. In many studies this effect has been disregarded when a statement was given that a material was probed below $\mathrm{Tg}$. To avoid relaxation processes from liquid fractions, an investigation of glasses should always performed below $T g_{0}$ or even better below $T g_{g}$. An equal disregard frequently appears with investigations of the liquid state, for example with measurements of viscosity covering as well the regime above $T g_{\text {liq }}$ as the range near $T g_{0}$.

\section{Conclusions}

The most important foundations of the new model are:

- the generation of apertures of a sufficient size by combinative mode amplification allowing molecular shifts,

- the limiting of volume $V g_{0}$ and following thereupon a defined time- and historyindependent, material-specific glass temperature $T g_{0}$ for all substances,

- $\quad$ the independence of $T g_{0}$ from $q T$

- the strong influence of the orientation of molecular axes and thereupon following variable possibilities for molecules to move through neighboring apertures,

- the existence of a material-specific intermediate limiting volume $V g_{l}$ for simple nonspherical molecules, below which molecular translation possibilities adopt a new quality,

- the importance of mode distribution approaching $V g_{0}$,

- a finite maximum value for equilibrium viscosity at $T g_{g}$,

- different viscosity behavior below and above the melting point of the crystalline phase,

- the dependence of the molecular transport processes on thermal expansion and size and the number of generated apertures.

In the author's opinion, the model presented here provides a consistent microscopic view of the glass transition and molecular processes within liquids. It considers the principle of thermophysical simplicity and can be verified by experiments.

\section{Prospects}

In part II of this work the experimental validation of the new model has been performed by multiple regression analysis with new viscosity equations which are based on the premises set out above. The new equations are in no case significantly worse and in the very most cases superior to the well-known equations of Vogel-Fulcher-Tamman (VFT), Doolittle, MCT, Bässler-Avramov, MYEGA, and to new proposed scaling procedures based on equations containing both volume and temperature first developed by Andrade 1934.

Part II deals with a few exceptions only with conditions in the supercooled region, but the basic equation developed by the author as early as 1980 is also applicable to the normal liquid region up to the critical point and at higher exterior pressures with pressuredependent terms without changing the basic parameters. (A working paper 2017 has been deposited at doi:10.13140/RG.2.2.21857.61286).

Funding: This research received no external funding.

Institutional Review Board Statement: Not applicable.

Informed Consent Statement: Not applicable.

Data Availability Statement: All data originate from the cited references.

Conflicts of Interest: The author declare no conflict of interest. 


\section{References}

1. Schmidtke, B.; Petzold, N.; Kahlau, R.; Hofmann, M.; Rössler, E.A. From Boiling Point to Glass Transition Temperature: Transport Coefficients in Molecular Liquids follow Three-parameter scaling. Phys. Rev. E 2012, 86, 041507. [CrossRef] [PubMed]

2. Chen, Z.; Angell, C.A.; Richert, R. On the Dynamics of Liquids in their Viscous Regime Approaching the Glass Transition. Eur. Phys. J. E 2012, 35, 1-7. [CrossRef] [PubMed]

3. Kob, W.; Berthier, L. Probing a Liquid to Glass transition in Equilibrium. Phys. Rev. Lett. 2013, 110, 245702. [CrossRef] [PubMed]

4. Sturm, K.G. Thermische Ausdehnung und Glasübergang als Bestimmungsgrößen der Viskosität von Flüssigkeiten. Rheol. Acta 1981, 20, 59-63. (In German) [CrossRef]

5. Leutheusser, E. Dynamical Model of the Liquid-Glass-Transition. Phys. Rev. A 1984, 29, 2765. [CrossRef]

6. Bengtzelius, U.; Götze, W.; Sjolander, A. Dynamics of Supercooled Liquids and the Glass Transition. J. Phys. C Solid State Phys. 1984, 17, 5915. [CrossRef]

7. Sjögren, L.; Götze, W. $\alpha$-Relaxation near the Glass Transition. J. Non-Cryst. Solids 1991, 131, 153-160.

8. Adam, J.H.; Gibbs, J. On the Temperature Dependence of Cooperative Relaxation Properties in Glass-Forming Liquids. Chem. Phys. 1965, 43, 139-146. [CrossRef]

9. Goldstein, M. Viscous Liquids and the Glass Transition: A Potential Energy Barrier Picture. J. Chem. Phys. 1969, 51, 3728-3739. [CrossRef]

10. Stillinger, F.H.; Weber, T.A. Hidden Structure in Liquids. Phys. Rev. A. 1982, 25, 978. [CrossRef]

11. Kirkpatrick, T.R.; Thirumalai, D.; Wolynes, P.G. Scaling concepts for the Dynamics of Viscous Liquids near an Ideal Glassy State. Phys. Rev. A 1989, 40, 1045-1054. [CrossRef] [PubMed]

12. Cummins, H.Z.; Li, G.; Hwang, Y.H.; Shen, G.Q.; Du, W.M.; Hernandez, J.; Tao, N.J. Dynamics of Supercooled Liquids and Glasses: Comparison of Experiments with Theoretical Predictions. Z. Phys. B 1997, 103, 501-519. [CrossRef]

13. Dyre, J.C. Colloquium: The Glass Transition and Elastic Models of Glass-Forming. Rev. Mod. Phys. 2006, 78, 953-972. [CrossRef]

14. Tanaka, H. Bond Orientational Ordering in Liquids: Towards a Unified Description of Water-like Anomalies, Liquid-Liquid Transition, Glass Transition, and Crystallization. Eur. Phys. J. E 2012, 35, 113. [CrossRef] [PubMed]

15. Liu, A.J.; Nagel, S.R. Non-linear Dynamics: Jamming is not just cool anymore. Nature 1998, 396, 21-22. [CrossRef]

16. Liu, A.J.; Nagel, S.R. The Jamming Transition and the Marginally Jammed Solid. Annu. Rev. Condens. Matter Phys. 2010, 1, 347-369. [CrossRef]

17. Kivelson, D.; Tarjus, S.A.; Zhao, X.; Kivelson, G. Fitting of Viscosity: Distinguishing the Temperature dependence predicted by various models of Supercooled Liquids. Phys. Rev. E 1996, 53, 751-757. [CrossRef] [PubMed]

18. Hecksher, T.; Nielsen, A.I.; Olsen, N.B.; Dyre, J.C. Little Evidence for Dynamic Divergences in Ultraviscous Molecular Liquids. Nat. Phys. 2008, 4, 737-741. [CrossRef]

19. Elmatad, Y.S.; Chandler, D.; Garrahan, J.P. Corresponding States of Structural Glass formers. J. Phys. Chem. B 2010, 114, 17113-17119. [CrossRef]

20. Pogna, E.A.A.; Rodriguez-Tinoco, C.; Cerullo, G.; Ferrante, C.; Rodriguez-Viejo, J.; Scopigno, T. Probing equilibrium glass flow up to exapois viscosities. Proc. Natl. Acad. Sci. USA 2015, 112, 2331-2336. [CrossRef]

21. Blodgett, M.; Engami, T.; Nussinow, Z.; Kelton, K.F. Unexpected Universality in the Viscosity of Metallic Liquids. arXiv 2014, arXiv:1407.7558. Available online: https:/ / arxiv.org/abs/1407.7558 (accessed on 6 October 2018).

22. Mc Laughlin, E.; Ubbelode, A.R. Cluster Formation in Relation to the Viscosity of Melts in the Pre-Freezing Region. Trans. Faraday Soc. 1958, 54, 1804-1810. [CrossRef]

23. Martinez-Garcia, J.C.; Rzoska, S.J.; Drozd-Rzoska, A.; Martinez-Garcia, J. A universal description of ultraslow glass dynamics. Nat. Commun. 2013, 4, 1823. [CrossRef]

24. Wang, L.-M.; Richert, R. Glass Transitions in Viscous Monohydroxy Alkohols: Calorimetric Versus Dielectric Ralaxation. Int. J. Thermophys. 2008, 29, 2055-2061. [CrossRef]

25. Kauzmann, W. The Nature of the Glassy State and the Behavior of Liquids at Low Temperatures. Chem. Rev. 1948, 43, 219-256. [CrossRef]

26. Tool, A.Q. Relation between inelastic deformability and thermal expansion of glass in its annealing range. J. Am. Ceram. Soc. 1946, 29, 240-253. [CrossRef]

27. Fox, T.G.; Flory, P.J. Second-Order Transition Temperatures and Related Properties of Polystyrene. I. Influence of Molecular Weight. J. Appl. Phys. 1950, 21, 581-591. [CrossRef]

28. Fox, T.G.; Flory, P.J. The Glass Temperature and Related Properties of Polystyrene. Influence of Molecular Weight. J. Polym. Sci. 1954, 14, 315-319. [CrossRef]

29. Ritland, H.N. Density Phenomena in the Transformation Range of a Borosilicate Glass. J. Am. Ceram. Soc. 1954, 37, 370-378. [CrossRef]

30. Rost, U. Das Viskositäts-Temperatur-Verhalten von Flüssigkeiten. Kolloid Z. 1955, 142, 132-150. [CrossRef]

31. Williams, M.L.; Landel, R.F.; Ferry, J.D. The Temperature Dependence of Relaxation Mechanisms in Amorphous Polymers and Other Glass-forming Liquids. J. Am. Chem. Soc. 1955, 77, 3701-3707. [CrossRef]

32. Cohen, D.; Turnbull, M.H. Molecular Transport in Liquids and Glasses. J. Chem. Phys. 1959, 31, 1164-1169. [CrossRef]

33. Kovacs, A.J. Transition Vitreuse dans les Polymères amorphes. Etude phènomènologique. Fortschr. Hochpolym. Forsch. 1963, 3 , 394-507. 
34. Barlow, J.; Lamb, J.; Matheson, A.J. Viscous Behaviour of Supercooled Liquids. Proc. R. Soc. Lond. 1966, 292, 322-343. [CrossRef]

35. Koppelmann, J. The Dependence of Relaxation Times on Free volume in high Polymers. In Proceedings of the Fourth International Congress on Rheology, Providence, RI, USA, 1 January 1965; Lee, E.H., Ed.; Interscience: New York, NY, USA, 1965 ; pp. 361-377.

36. Rötger, H. Zeitabhängige physikalische Eigenschaften von Gläsern. Wiss. Fortschr. 1968, 6, 260-274.

37. Plazek, D.J.; Magill, J.H. Physical Properties of Aromatic Hydrocarbons. I. Viscous and Elastic Behavior of 1,3,5 tri- $\alpha$ naphthylbenzene. J. Chem. Phys. 1966, 45, 3038-3050. [CrossRef]

38. Plazek, D.J.; Magill, J.H. Physical Properties of Aromatic Hydrocarbons. IV. An analysis of the Temperature Dependence of the Viscosity and the Compliance of 1,3,5 tri- $\alpha$-naphthylbenzene. J. Chem. Phys. 1968, 49, 3678-3682. [CrossRef]

39. Plazek, D.J.; Bero, C.A.; Chay, I.-C. The Recoverable Compliance of Amorphous Materials. J. Non-Cryst. Solids 1994, 172-174, 181-190. [CrossRef]

40. Plazek, D.J.; Magill, J.H.; Echeverria, I.; Chay, I.-C. Viscoelastic Behavior of 1,3,5 tri $\alpha$-naphthyl benzene will the real T $\alpha$ NB please stand up. J. Chem. Phys. 1999, 110, 10445-10451. [CrossRef]

41. Davies, D.B.; Matheson, A.J. Influence of Molecular Rotation on the Viscosity of Liquids. J. Chem. Phys. 1966, 45, 1000-1009. [CrossRef]

42. Breuer, H.; Rehage, G. Zur Thermodynamik der glasigen Erstarrung. Colloid Polym. Sci. 1967, 216, 159-179. [CrossRef]

43. Kanig, G. Das freie Volumen und die Änderung des Ausdehnungskoeffizienten und der Molwärme bei der Glasübergangstemperatur von Hochpolymeren. Colloid Polym. Sci. 1969, 233, 829-844.

44. Donth, E.-J. Glasübergang; Akademie-Verlag: Berlin, Germany, 1981.

45. Mckenna, G.B.; Angell, C.A. The phenomenology and models of the kinetics of volume and enthalpy in the glass transition range. J. Non-Cryst. Solids 1991, 131-133, 528-536. [CrossRef]

46. Brüning, R.; Samwer, K. Glass transition on long time scales. Phys. Rev. B 1992, 46, 11318-11322. [CrossRef] [PubMed]

47. Böhmer, R.; Ngai, K.L.; Angell, C.A.; Plazek, D.J. Nonexponential Relaxations in Strong and Fragile Glass Formers. J. Chem. Phys. 1993, 99, 4201-4209. [CrossRef]

48. Angell, C.A. Formation of Glasses from Liquids and Biopolymers. Science 1995, 267, 1924-1935. [CrossRef]

49. Ediger, M.D.; Angell, C.A.; Nagel, S.R. Supercooled Liquids and Glasses. J. Phys. Chem. 1996, 100, 13200-13212. [CrossRef]

50. Colucci, D.M.; McKenna, G.B.; Filiben, J.J.; Lee, A.; Curliss, D.B.; Bowman, K.B.; Russel, J.D. Isochoric and Isobaric Glass Formation: Similarities and Differences. J. Polym. Sci. B Polym. Phys. 1997, 35, 1561-1573. [CrossRef]

51. Rössler, E.; Hess, K.-U.; Novikov, V.N. Universal Representation of Viscosity in Glass Forming Liquids. J. Non-Cryst. Solids 1998, 223, 207-222. [CrossRef]

52. Ngai, K.L. Dynamic and Thermodynamic Properties of Glass-forming Substances. J. Non-Cryst. Solids 2000, 375, 7-51. [CrossRef]

53. Tarjus, G.; Kivelson, D. The Viscous Slowing Down of Supercooled Liquids and the Glass Transition: Phenomenology, Concepts, and Models. In Jamming and Rheology: Constrained Dynamics on Microscopic and Macroscopic Scales; Taylor and Francis Group: London, UK, 2001.

54. Berthier, L.; Garrahan, J.P. Real Space Origin of Temperature Crossovers in Supercooled Liquids. Phys. Rev. E 2003, 68, 041201. [CrossRef] [PubMed]

55. Yue, Y.; Ohe, R.V.D.; Jensen, S.L. Fictive temperature, cooling rate, and viscosity of glasses. J. Chem. Phys. 2004, 120, 8053-8059. [CrossRef] [PubMed]

56. Tanaka, H. Two-Order-Parameter Model of the Liquid-Glass Transition. I. Relation between Glass Transition and Crystallization. J. Non-Cryst. Solids 2005, 351, 3371-3384. [CrossRef]

57. Ojovan, M.I. Viscosity and Glass Transition in Amorphous Oxides. Adv. Condens. Matter Phys. 2008, 2008, 817829. [CrossRef]

58. Hutchinson, J.M. Determination of the glass transition temperature Methods correlation and structural heterogeneity. J. Therm. Anal. Calorim. 2009, 98, 579-589. [CrossRef]

59. Tarjus, G. An Overview of the Theories of the Glass Transition. In Dynamical Heterogeneities in Glasses, Colloids and Granular Media; Oxford University Press: Oxford, UK, 2011.

60. Berthier, L.; Biroli, G. Theoretical Perspective on the Glass Transition and Amorphous Materials. Rev. Mod. Phys. 2011, 83, 587. [CrossRef]

61. Stillinger, F.; Debenedetti, P.G. Glass Transition Thermodynamics and Kinetics. Ann. Rev. Condens. Matter Phys. $2013,4,263-285$. [CrossRef]

62. Biroli, G.; Garrahan, J.P. Perspective: The Glass Transition. J. Chem. Phys. 2013, 138, 12A301. [CrossRef] [PubMed]

63. Langer, J.S. Theories of Glass Formation and the Glass Transition. Rep. Prog. Phys. 2014, 77, 042501. [CrossRef]

64. Miracle, D.B.; Senkov, O.N. A critical review of high entropy alloys and related concepts. Acta Mater. 2017, 122, 448-511. [CrossRef]

65. Schmelzer, J.W.E.; Tropin, T.V. Glass Transition, Crystallization of Glass-forming Melts, and Entropy. Entropy 2018, $20,103$. [CrossRef] [PubMed]

66. Zheng, Q.; Zhang, Y.; Montazerian, M.; Gulbiten, O.; Mauro, J.C.; Zanotto, E.D.; Yue, Y. Understanding Glass through Differential Scanning Calorimetry. Chem. Rev. 2019, 119, 7848-7939. [CrossRef]

67. Batschinski, A.J. Untersuchung über die innere Reibung der Flüssigkeiten. Z. Phys. Chem. 2013, 84, 643-706.

68. Hirschfelder, J.O.; Stevenson, D.; Eyring, H. A theory of liquid structure. J. Chem. Phys. 1939, 5, 896-912. [CrossRef] 
69. Hirschfelder, J.O.; Curtiss, C.F.; Bird, R.B. Molecular Theory of Gases and Liquids; John Wiley and Sons Inc.: New York, NY, USA, 1954.

70. Grest, G.S.; Cohen, M.H. Liquids, Glasses and the Glass Transition: A Free Volume Approach. In Advances in Chemical Physics; Prigogine, I., Rice, S.A., Eds.; John Wiley and Sons Inc.: Hoboken, NJ, USA, 1981; Volume 48.

71. Glasstone, S.; Laidler, J.; Eyring, H. The Theory of Rate Processes; McGraw-Hill Book Co., Inc.: New York, NY, USA, 1941.

72. Chen, H.S.; Turnbull, D. Evidence of a Glass-Liquid Transition in a Gold-Germanium-Silicon-Alloy. J. Chem. Phys. 1968, 48, 2560-2571. [CrossRef]

73. Kamien, R.D.; Liu, A.J. Why is Random Close Packing Reproducible. Phys. Rev. Let. 2007, 99, 155501. [CrossRef] [PubMed]

74. Scott, G.D. Packing of Spheres: Packing of Equal Spheres. Nature 1960, 188, 908-909. [CrossRef]

75. Doolittle, A.K. Studies in Newtonian Flow. II. The Dependence of Viscosity of Liquids on Free-Space. J. Appl. Phys. 1951, 22, 1471-1475. [CrossRef]

76. Simha, R.; Weil, C.E. Concerning Free Volume Quantities and the Glass Temperature. J. Macromol. Sci. Phys. 1970, 4, 215-226. [CrossRef]

77. Sturm, K.G. Zur Temperaturabhängigkeit der Viskosität von Flüssigkeiten. Glastechnologie 1980, 53, 63-76.

78. Blazhnov, I.V.; Malomuzh, M.P.; Lishchuk, S.V. Temperature Dependence of Density, Thermal Expansion Coefficient and Shear Viscosity of Supercooled Glycerol as a Reflection of its Structure. J. Chem. Phys. 2004, 121, 6435-6441. [CrossRef] [PubMed]

79. Dyre, J.C. On the Possible Existence of Crystallites in Glass-Forming Liquids. arXiv 2006, arXiv:cond-mat/0612671. Available online: https: / / arxiv.org/abs/cond-mat/0612671 (accessed on 3 November 2019).

80. Semmelhack, H.C.; Esquinazi, P. Observation of Metastable Ordered Structures and the Kinetics of Crystallization of o-Terphenyl. Physica B 1998, 254, 14-20. [CrossRef]

81. Baran, J.; Davidova, N.A.; Drozd, M.; Ponezha, E.A.; Reznichenko, V.Y. Nature of the Dynamic crossover in Orthoterphenyl. Ukr. J. Phys. 2014, 59, 292-298. [CrossRef]

82. Mazurin, O. Einige Aspekte des heutigen Standes der kinetischen Theorie der Glastransformation. Silikattechnik 1973, $24,293-295$.

83. Narayanaswamy, O.S. A Model of Structural Relaxation in Glass. J. Am. Ceram. Soc. 1971, 54, 491-498. [CrossRef]

84. Moynihan, C.T.; Macedo, P.B.; Montrose, C.J.; Gupta, P.K.; DeBolt, M.A.; Dill, J.F.; Dom, B.E.; Drake, P.W.; Esteal, A.J.; Elterman, P.B.; et al. Structural Relaxation in Vitreous Materials. Ann. N. Y. Acad. Sci. 1976, 279, 15-35. [CrossRef]

85. Scherer, G.W. Theories of Relaxation. J. Non-Cryst. Solids 1990, 240, 75-89. [CrossRef]

86. McKenna, G.B.; Zhao, J. Accumulating evidence for non-diverging time-scales in glass-forming fluids. J. Non-Cryst. Solids 2015, 407, 3-13. [CrossRef]

87. Zanotto, E.D.; Mauro, J.C. The glassy state of matter: Its definition and ultimate fate. J. Non-Cryst. Solids 2017, 471, 490-495. [CrossRef]

88. Nemilov, S.V. On the possibility of Calculating Entropy, Free Energy, and Enthalpy of Vitreous substances. Entropy 2018, 20, 187. [CrossRef]

89. Angell, C.A. Relaxation in liquids, polymers and plastic crystals-Strong/fragile patterns and problems. J. Non-Cryst. Solids 1991, 131, 13-31. [CrossRef]

90. Yamamuro, O.; Tsukushi, I.; Lindquist, A.; Takahara, S.; Ishikawa, M.; Matsuo, T. Calorimetric Study of Glassy and Liquid Toluene and Ethylbenzene: Thermodynamic Approach to Spatial Heterogeneity in Glass-Forming Molecular Liquids. J. Phys. Chem. B 1998, 102, 1605-1609. [CrossRef]

91. Stevenson, J.D.; Wolynes, P.G. The Ultimate Fate of Supercooled Liquids. J. Phys. Chem. A 2011, 115, 3713-3719. [CrossRef] [PubMed]

92. Kearns, K.L.; Swallen, S.F.; Ediger, M.D. Influence of substrate temperature on the stability of glasses prepared by vapor deposition. J. Chem. Phys. 2007, 127, 154702. [CrossRef] [PubMed]

93. Kearns, K.L.; Swallen, S.F.; Ediger, M.D. Hiking down the Energy Landscape: Progress toward the Kauzmann Temperature via Vapor Deposition. J. Phys. Chem. B 2008, 112, 4934-4942. [CrossRef]

94. Ahrenberg, M.; Chua, Y.Z.; Whitaker, K.R.; Huth, H.; Ediger, M.D.; Schick, C. In situ investigation of vapor-deposited glasses of toluene and ethylbenzene via alternating current chip-nanocalorimetry. J. Chem. Phys. 2013, 138, 024501. [CrossRef]

95. Zondervan, R.; Xia, T.; van der Meer, H.; Storm, C.; Kulzer, F.; van Saarlos, W.; Orrit, M. Soft glass rheology of supercooled molecular liquids. Proc. Natl. Acad. Sci. USA 2008, 105, 4993-4998. [CrossRef] [PubMed]

96. Krüger, J.K.; Britz, T.; Baller, J.; Possart, W.; Neurohr, H. Thermal Glass Transition Beyond the Vogel-Fulcher-Tamman Behavior for Glass Forming Diglycidylether of Bisphenol A. Phys. Rev. Lett. 2002, 89, 285701. [CrossRef] [PubMed]

97. Xia, L.; Tang, M.B.; Xu, H.; Pan, M.X.; Zhao, D.Q.; Wang, W.H.; Dong, Y.D. Kinetic Nature of Hard $\mathrm{Magnetic} \mathrm{Nd}_{50} \mathrm{Al}_{15} \mathrm{Fe}_{15} \mathrm{Co}_{20}$ Bulk Metallic glass. J. Mater. Res. 2004, 19, 1307-1310. [CrossRef]

98. Bero, C.A.; Plazek, D.J. Volume Dependent Rate Processes in an Epoxy Resin. J. Polym. Sci. Part B Polym. Phys. 1991, $29,39-47$. [CrossRef]

99. Rötger, H. Glasausdehnungsverlauf und Einfriertemperatur. Silikattechnik 1969, 20, 404-407.

100. DeBolt, M.A.; Esteal, A.J.; Macedo, P.B.; Moynihan, C.T. Analysis of Structural Relaxation in Glass Using Rate Heating Data. J. Am. Ceram. Soc. 1976, 59, 16-21. [CrossRef]

101. Döß, A.; Hinze, G.; Schiener, B.; Hemberger, J.; Böhmer, R. Dielectric Relaxation in the Fragile Viscous Liquid State of Toluene. J. Chem. Phys. 1997, 107, 1740-1743. [CrossRef] 
102. Brüning, R.; Crowell, T. A Method to Determine the Kinetics of a Supercooled Liquid by Temperature Scanning Measurements Applied to (Li, Na)acetate and GeO2. J. Non-Cryst. Solids 1999, 248, 183-193. [CrossRef]

103. Greiner, R.; Schwarzl, F.R. Thermal Contraction and Volume Relaxation of Amorphous Polymers. Rheol. Acta 1984, 23, 378-395. [CrossRef]

104. Hadač, J.; Slobodian, P.; Říha, P.; Sáha, P.; Rychwalski, R.W.; Emri, I.; Kubát, J. Effect of Cooling Rate on Enthalpy and Volume Relaxation of Polystyrene. J. Non-Cryst. Solids 2007, 353, 2681-2691. [CrossRef]

105. Schawe, J.E.K. Measurement of the thermal glass transition of polystyrene in a cooling rate range of more than six decades. Thermochim. Acta 2015, 603, 128-134. [CrossRef]

106. Richardson, M.J.; Savill, N.G. Derivation of accurate glass transition temperatures by differential scanning calorimetry. Polymer 1975, 16, 753-757. [CrossRef]

107. Moynihan, C.T.; Easteal, A.J.; DeBolt, M.A.; Tucker, J. Dependence of the fictive temperature of glasses on cooling rate. J. Am. Ceram. Soc. 1976, 59, 12-16. [CrossRef]

108. Sturm, K.G. Microscopic Model of Glass Transformation and Molecular Translation in Liquids III-Supercooled Liquids 2. B2O3-KCN 60/40-TNB-2-MP. Available online: https:/ /www.researchgate.net/publication/295260824_Microscopic_Model_ of_Glass_Transformation_and_Molecular_Translation_in_Liquids_III_Supercooled_liquids_-_2_B203_-KCaNO3_6040_-_3NAB_-2-MP_Needs_revision (accessed on 8 June 2021).

109. Holubová, J.; Černošek, Z.; Černošková, E. The Study of the Glass Transition by the Stepscan DSC Technique. J. Optoelectron. Adv. Mater. 2005, 7, 2671-2676.

110. Chromčíková, M.; Holubová, J.; Liška, M.; Černošek, Z.; Černošková, E. Modeling of the Reversible Part of Stepscan DSC Measurements of the Glass Transition. Ceramics-Silicaty 2005, 49, 91-96. 